\title{
The Possible Physical Mechanism for the EAP-SR co-action
}

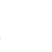

(1)

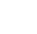

(1)

(1)

(1)

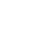

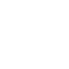

.

Muhammad Mubashar Dogar

Earth Science and Engineering Department, King Abdullah University of Science and

Technology, Thuwal, Saudi Arabia

Global Change Impact Studies Centre, Ministry of Climate Change, Islamabad,

Pakistan

(1)

2
3 24

\author{
Zhiqiang Gong
}

Laboratory for Climate Studies, National Climate Research Center CMA,

Beijing 100081, China;

\section{Guolin Feng}

Laboratory for Climate Studies, National Climate Research Center CMA,

Beijing 100081, China; Pakistan

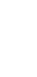

Gang Huang

Institute of Atmospheric Physics,

Chinese Academy of Sciences, 100029, Beijing, China

Corresponding author: gongzq@126.com 


\begin{abstract}
\end{abstract}
The anomalous characteristics of summer precipitation and atmospheric circulation in the East Asia-West Pacific Region (EA-WP) associated with the co-action of East Asia/Pacific teleconnection - Silk Road teleconnection (EAP-SR) are investigated in this study. The compositions of EAP-SR phase anomalies can be expressed as pattern I $(++)$, pattern II $(+-)$, pattern III (- -), and pattern IV (- +) using EAP and SR indices. It is found that the spatial distribution of summer precipitation anomalies in EA-WP corresponding to pattern I (III) shows a tripole structure in the meridional direction and a zonal dipole structure in the subtropical region, while pattern II (Saha et al.) presents a tripole pattern in meridional direction with compressed and continuous anomalies in the zonal direction over the subtropical region. The similar meridional and zonal structures are also found in the geopotential height anomalies at $500 \mathrm{hPa}$, as well as wind anomalies and moisture convergence at $850 \mathrm{hPa}$. Finally, a schematic mechanism for the EAP-SR co-action upon the summer precipitation in EA-WP is built: (1) Pattern I (III) implies negative (positive) Sea Surface Temperature (SST) anomalies over the tropical West Pacific, which weakens (strengthens) the thermal convective activity, and induces anomalous downward (upward) motion, causing negative (positive) geopotential height anomalies at the middle troposphere $(500 \mathrm{hPa})$ over the South China Sea and surrounding regions through the function of the tropical Hadley circulation. The negative (positive) geopotential height anomalies could motivate the positive (negative) EAP teleconnection through the northward propagation of wave-activity perturbation. Meanwhile, a positive (negative) geopotential height anomalous pattern over Eastern Europe motivates a Rossby wave train propagation from Western Europe to west-central Asia. That causes suppressed (enhanced) convection and less (more) precipitation over northwestern 
India and Pakistan, which could strengthen the negative (positive) geopotential height and positive (negative) vorticity anomalies over central East Asia, resulting in a negative (positive) SR teleconnection along the Asian jet stream. A positive (negative) lobe over the Korean Peninsula and Japan corresponding to SR overlaps with a positive (negative) lobe of EAP, which strengthens the anomalous phase contrast on both sides of $120^{\circ} \mathrm{E}$. Accordingly, summer precipitation anomalies in EA-WP exhibit the meridional tripole pattern and the zonal dipole pattern. (2) Pattern II (Saha et al.) indicates a positive (negative) SST anomalies over the tropical West Pacific, leading to a negative (positive) lobe of EAP over the subtropical region. This circumstance can weaken the positive (negative) lobe of SR over subtropical region, causing compressed and continuous negative (positive) anomalies of 500-hPa geopotential height and surface precipitation anomalies from central East China to Japan.

Keywords, East Asia/Pacific teleconnection, Silk Road teleconnection, Co-action, Precipitation

\section{Introduction}

The East Asia Summer Monsoon (EASM) is an important subsystem of the global climate system.

The EASM has obvious interannual variability and causes severe droughts and floods in China, the Korean peninsula, Japan and many other parts of East and South Asia (Nitta \& Hu 1996, Huang et al. 1998, Wang et al. 2001). Therefore, the interannual variability of the EASM, especially the spatial and temporal variability of summer precipitation over East Asia, has always been an imperative research task deserving interest and attention from meteorologists involved in climate diagnosis and prediction (Webster \& Yang 1992, Huang et al. 1993, Yang \& Lau 2004, Gong et al. 2015b). Studying the leading teleconnection modes and associated climatic impacts 
are important for better understanding of the global and regional climate system, especially the South Asian and the East Asian monsoon systems (Dogar et al. 2017).

Summer precipitation over the East Asia-West Pacific region (EA-WP) is influenced by the northwestern Pacific subtropical high (PASH), which is part of the EASM system. The northward movement and westward extension of PASH influences the moisture transportation from low latitude to mid-high latitude areas. They cause anomalous convective activities over the northwestern Pacific and coastal areas that trigger severe drought and flooding events in EA (Huang et al. 1998, Ding \& Chan 2005, Li et al. 2008). The PASH is characterized by interactions among its components in the meridional direction ( $\mathrm{Lu}$ 2004), i.e., either the East Asia-Pacific (EAP) teleconnection (Huang 1987) or the Pacific-Japan (PJ) teleconnection (Nitta 1987) plays an important role in mediating influence of PASH on summertime climate in EA-WP. The obvious meridional tripole pattern from the tropics pole-ward to the extra-tropics, triggered by anomalies of convective activities over the tropical western Pacific, causes the summertime moisture transportation fluxes and precipitation in East Asia. This mechanism presents the corresponding tripole pattern on different time scales (Huang et al. 2012a). The EAP pattern has been used to explain the internal process of the meridional tripole pattern of the spatial and temporal variability of the EASM system on interannual and interdecadal scales (Huang et al. 2006, Huang et al. 2012b). Accordingly, the spatial distributions of summertime drought and flood events over East Asia have a similar characteristic of the meridional tripole pattern as the EAP teleconnection (Huang et al. 2007). 
91 Meanwhile, the Silk Road (SR) teleconnection (Enomoto et al. 2003), as a wave-like pattern

observed from the meridional wind field at $200 \mathrm{hPa}$, is another dominant teleconnection pattern that influences summer climate in EA-WP. SR especially influences the interannual variability of PASH from the zonal direction (Takaya \& Nakamura 2001, Kosaka et al. 2009, Chen et al. 2013). Tao (2006) suggests that the propagation of the Rossby wave train along the jet stream across the Eurasian continent to East Asia at the upper levels may influence the south-northward advance and retreat of the summer PASH. This process may further influence the onset and offset date of the summer precipitation season over East Asia (Feng et al. 2013, Gong et al. 2015a, Gong et al. 2016). Kosaka et al. (2012) also revealed that the SR pattern, another dominant teleconnection that influences the northwestern PASH and East Asia, is unpredictable at monthly to seasonal leading time scale, limiting the seasonal predictability of summer precipitation in East Asia.

Based on the above discussion, the meridional pattern of summer precipitation anomalies over EA-WP has correlations with both EAP and SR teleconnections. Furthermore, Lu (2004) revealed that the interaction of SR with EAP modulates the EAP teleconnection exhibiting an intraseasonal difference between early summer and late summer. Kosaka et al. (2012) analyzed the interference of SR teleconnection to the anomalous summer climate of 2010 in East Asia. These studies imply that the EAP teleconnection pattern can be modulated by the SR teleconnection. Hsu and Lin (2007) further presented the relationship of the tripole summer precipitation pattern with both PJ and SR teleconnections, revealed that PJ teleconnection is more evident in the positive phase of summer precipitation, while the SR pattern is more evident in the negative phase. 
In view of the above statement, although the EAP and SR patterns have been revealed, the mechanism of co-action of EA and SR on influencing the precipitation anomalous pattern in EA-WP is still obscure. For example, there are still remaining questions such as (1) along with the meridional tripole pattern, is there any other zonal pattern of summer precipitation caused by the co-influence of EAP and SR, and (2) if so, what are internal processes and external forces leading to the zonal anomalous pattern? Therefore, it is worthwhile to explore atmospheric circulation and precipitation anomaly patterns in EA-WP originating from different EAP-SR compositions, and the relevant physical mechanism.

In this study, we use the EAP index (Huang 2004) and a defined SR index to identify their probable compositions in different phases. Then, the distinct anomalous patterns of precipitation and atmospheric circulation in EA-WP that correspond to EAP-SR compositions, which have been unnoticed in previous studies, are presented in section 3. In section 4, we discuss the possible physical mechanism of EAP and SR compositions through the analysis of thermal convective activity and wave-activity propagation. The SST anomalies and wave patterns corresponding to EAP-SR compositions are presented in section 5. Finally, conclusions and brief discussions are given in section 6.

\section{Data and method}

Atmospheric circulation data used in this study includes the monthly data from NCEP Re-Analysis in terms of the geopotential height, wind, omega, specific humidity at different levels from 1979 to 2015 (Masao et al. 2002). Data of Outgoing Long wave Radiation (OLR) and surface pressure from 1979-2015 is also from NCEP Re-Analysis. The CPC Merged Analysis of 
Precipitation (CMAP) monthly precipitation observation dataset from 1979 to 2015 is interpolated to a horizontal resolution of $2.5^{\circ} \times 2.5^{\circ}$. The reconstructed monthly Global Sea Surface Temperature (SST) dataset from 1979 to 2015 is COBE SST produced by Japan Meteorological Administration (Ishii et al. 2005) .

The EAP teleconnection index (Huang 2004) is defined in formula (1),

$$
I_{E A P}=-0.25 Z^{\prime}\left(60^{\circ} \mathrm{N}, 125^{\circ} \mathrm{E}\right)+0.5 Z^{\prime}\left(40^{\circ} \mathrm{N}, 125^{\circ} \mathrm{E}\right)-0.25 Z^{\prime}\left(20^{\circ} \mathrm{N}, 125^{\circ} \mathrm{E}\right)
$$

where $Z^{\prime}=\sin 45 / \sin \varphi(Z-\bar{Z})$ is the standardized seasonal mean $500 \mathrm{hPa}$ anomaly at a grid point with the latitude $\varphi$.

Similar to the definition of EAP index, the SR teleconnection index is defined in formula (2),

$$
I_{S R}=-0.25 V^{\prime}\left(40^{\circ} \mathrm{N}, 80^{\circ} \mathrm{E}\right)+0.5 V^{\prime}\left(40^{\circ} \mathrm{N}, 110^{\circ} \mathrm{E}\right)-0.25 V^{\prime}\left(40^{\circ} \mathrm{N}, 140^{\circ} \mathrm{E}\right)
$$

where $V^{\prime}=\sin 45^{\circ} / \sin \varphi(V-\bar{V})$ is the standardized seasonal mean meridional wind velocity anomaly of a grid point with the latitude $\varphi$ at the level 200-hPa.

\section{The vertically integrated moisture flux $(Q)$ in the troposphere from the surface to $200-\mathrm{hPa}$ is} calculated by:

$$
\vec{Q}=\frac{1}{g} \int_{200}^{P_{s}} q \vec{V} d p
$$

where $g, q, V$, and $p_{s}$ are the acceleration of gravity, specific humidity, horizontal wind vector, and surface pressure, respectively (Li et al. 2012).

In order to validate whether indices of EAP and SR well represent the two teleconnection patterns, correlation coefficients (CCs) of EAP and SR indices, along with other existing indices 
representing the same teleconnection pattern, are presented in Table 1. Most CCs are above the 95\% significance level. The correlation coefficient (Kosaka et al. 2013) of the EAP index defined as proposed by Huang et al (2004), has a CC 0.58 with PC- $1_{z 500}$ reaches 0.58 , indicating that the EAP index of this study could reflect the precipitation features over East Asia. Since the circumglobal teleconnection index (CGTI) suggested by Ding and Wang (2005) and Ding et al. (2011) could well explain precipitation anomalies over the subtropical region in northern hemisphere, CC of SR index with CGTI reaches 0.62 , implying the SR index defined in the study could reflect the SR teleconnection.

Table 1. Correlation coefficients of EAP index and SR index with other similar indices.

\begin{tabular}{|c|c|c|c|}
\hline & EAP & & SR \\
\hline PC-1 2500 & 0.58 & $P C-4_{v 200}$ & 0.88 \\
\hline PC-2 2200 & 0.32 & CGTI & 0.62 \\
\hline $\mathbf{P C}-\mathbf{3}_{\mathrm{Z} 200}$ & 0.52 & $\mathrm{PC}-5_{\mathrm{Z} 200}$ & 0.26 \\
\hline WNPSMI & 0.36 & - & - \\
\hline
\end{tabular}

Note, Indices compared with EAP include the first principle component of 500-hPa height (PC-1 $\left.1_{\mathrm{Z} 500}\right)$ over the region $\left(10^{\circ} \mathrm{N}-70^{\circ} \mathrm{N}, 90^{\circ} \mathrm{E}-160^{\circ} \mathrm{E}\right)$, the PC2 of the north hemispheric 200 -hPa geopotential height anomalies (PC-2Z200) (Ding et al. 2011), the PC3 of the 200-hPa height (PC-3Z200) over the region $\left(0-80^{\circ} \mathrm{N}, 70^{\circ} \mathrm{E}-160^{\circ} \mathrm{E}\right)$, the western Pacific-North America teleconnection index (WNPSMI) defined as the meridional shear of the $850-\mathrm{hPa}$ westerly, in terms of the 850 -hPa zonal winds averaged over the southern region $\left(5^{\circ} \mathrm{N}-15^{\circ} \mathrm{N}, 100^{\circ} \mathrm{E}-130^{\circ} \mathrm{E}\right)$ minus that averaged over the northern region $\left(20^{\circ} \mathrm{N}-30^{\circ} \mathrm{N}, 110^{\circ} \mathrm{E}-140^{\circ} \mathrm{E}\right.$ ) (Wang et al. 2001). Indices compared with SR include the first principle 
177

region $\left(20^{\circ} \mathrm{N}-60^{\circ} \mathrm{N}, 30^{\circ} \mathrm{E}-160^{\circ} \mathrm{E}\right)$, and the circumglobal teleconnection pattern index (CGTI) defined by average of the $200-\mathrm{hPa}$ geopotential height over the region $\left(35^{\circ} \mathrm{N}-40^{\circ} \mathrm{N}, 60^{\circ} \mathrm{E}-70^{\circ} \mathrm{E}\right)(\mathrm{Ding} \&$ Chan 2005).

The formula (4) is used to calculate the wave-activity flux $\mathrm{W}$ in pressure $(p)$ coordinates (Hoskins \& Karoly 1981, Gong et al. 2013, Qiao et al. 2015):

$$
W=\frac{1}{2|\bar{U}|}\left(\begin{array}{c}
\bar{u}\left[\left(\frac{\partial \Psi^{\prime}}{\partial x}\right)^{2}-\Psi^{\prime} \frac{\partial^{2} \Psi^{\prime}}{\partial x x}\right]+\bar{v}\left[\frac{\partial \Psi^{\prime}}{\partial x} \frac{\partial \Psi^{\prime}}{\partial y}-\Psi^{\prime} \frac{\partial^{2} \Psi^{\prime}}{\partial x \partial y}\right] \\
\bar{u}\left[\frac{\partial \Psi^{\prime}}{\partial x} \frac{\partial \Psi^{\prime}}{\partial y}-\Psi^{\prime} \frac{\partial^{2} \Psi^{\prime}}{\partial x \partial y}\right]+\bar{v}\left[\left(\frac{\partial \Psi^{\prime}}{\partial y}\right)^{2}-\Psi^{\prime} \frac{\partial^{2} \Psi^{\prime}}{\partial y y}\right] \\
\frac{f_{0}^{2}}{R \sigma / p}\left\{\bar{u}\left[\frac{\partial \Psi^{\prime}}{\partial x} \frac{\partial \Psi^{\prime}}{\partial p}-\Psi^{\prime} \frac{\partial^{2} \Psi^{\prime}}{\partial x \partial p}\right]+\bar{v}\left[\frac{\partial \Psi^{\prime}}{\partial y} \frac{\partial \Psi^{\prime}}{\partial p}-\Psi^{\prime} \frac{\partial^{2} \Psi^{\prime}}{\partial y \partial p}\right]\right\}
\end{array}\right)
$$

Where $\Psi$ is the stream-function, $f$ the Coriolis parameter, $R$ the gas constant, $\boldsymbol{U}=(u, v)$ the horizontal wind velocity, and $\sigma=\frac{R T}{C_{p} P}-d T / d p$, with temperature, $T$ and the specific heat at constant pressure, $C_{p}$. Over bars and primes denote basic-state quantities and perturbations, respectively. Analysis of this study in terms of precipitation, circulations, EAP SR teleconnections are conducted for the summertime (June, July and August, JJA).

3. EAP and SR teleconnection and corresponding composition patterns.

Fig 1 (a) shows the first spatial mode (with $30.2 \%$ contribution to total variance) extracted through an empirical orthogonal function (EOF) analysis applied to interannual anomalies of summer geopotential height anomalies at $500 \mathrm{hPa}$ during 1979-2015. This mode has a similar spatial characteristic to the EAP teleconnection (Huang 1987, Huang 2004). In this pattern, summer geopotential anomalies are characterized by a meridional tripole anomalous pattern in the low-latitudes $\left(20^{\circ}-30^{\circ} \mathrm{N}\right)$, mid-latitudes $\left(35^{\circ}-50^{\circ} \mathrm{N}\right)$, and high-latitudes $\left(55^{\circ}-70^{\circ} \mathrm{N}\right)$ region of 
197

198

199

200

201

202

203

EA-WP (Fig. 1 a). Compared to the definition of PJ teleconnection (Nitta 1987), there is one more extended anomalous lobe located in high-latitude region. The first spatial mode of EOF (with $25.2 \%$ contribution to total variance) of the summer meridional wind velocity at $200-\mathrm{hPa}$ is shown in Fig. 1(b), which indicates the SR teleconnection. The SR pattern is dominated by a quasi-stationary Rossby wave train in the upper troposphere along the summer Asian jet region $\left(30^{\circ}-50^{\circ} \mathrm{N}\right)$. SR pattern has four anomalous lobes located at $\left(50^{\circ} \mathrm{E}, 40^{\circ} \mathrm{N}\right),\left(80^{\circ} \mathrm{E}, 40^{\circ} \mathrm{N}\right),\left(110^{\circ} \mathrm{E}, 40^{\circ} \mathrm{N}\right)$, and $\left(140^{\circ} \mathrm{E}, 40^{\circ} \mathrm{N}\right)$, respectively, which are consistent with previous definitions (Enomoto et al. 2003,

Ding \& Wang 2005).

(a)H50O EOF 1
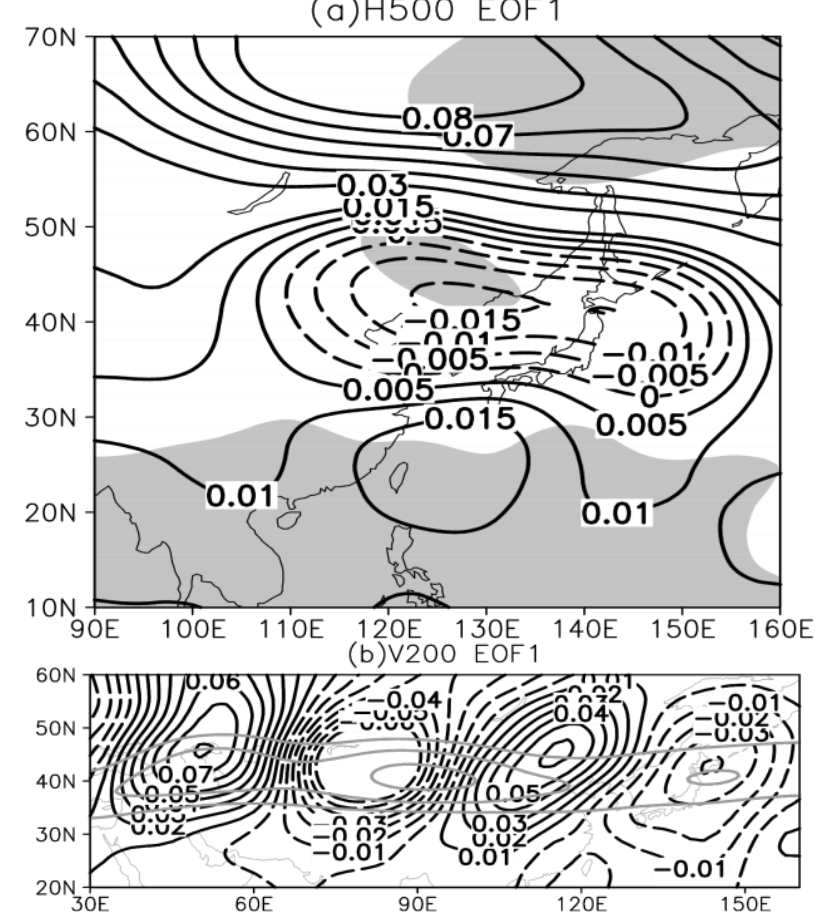

FIG. 1. Spatial pattern of the EOF1 for summer anomalies of (a) 500-hPa geopotential height (unit: gpm) over $\left[10-70^{\circ} \mathrm{N}, 90-160^{\circ} \mathrm{E}\right]$ and (b) $200-\mathrm{hPa}$ meridional wind velocity (units: $\mathrm{ms}^{-1}$ ) over $\left[20-60^{\circ} \mathrm{N}, 30-160 \mathrm{E}^{\circ}\right]$ during 1981-2010. Gray lines in (b) denote 20 and $25 \mathrm{~ms}^{-1}$ contours of the climatological-mean zonal wind velocity, which indicate the Asian jet waveguide. Shadings in (a) indicate the $95 \%$ significance level of regression of 500-hPa geopotential height onto the first principle component. 
214 To reveal these teleconnection patterns more clearly, Fig. 2 (a) presents the meridional cross

215 section of these wavelike perturbations regressed onto the first principle component (PC1) of Fig.

2161 (a). The regressed anomalies along $120^{\circ} \mathrm{E}$ exhibit a poleward wavelike pattern in the meridional

217 direction. From the lower troposphere to the upper troposphere, positive anomalies with maximum amplitude are observed around $20^{\circ} \mathrm{N}$ and $70^{\circ} \mathrm{N}$, while negative anomalies distribute around $40^{\circ} \mathrm{N}$.

219 This situation indicates that the wavelike pattern has an equivalent barotropic structure with slight northward tilting in the vertical direction. Statistically, significantly correlated regions further identify the tripole pattern is consistent with the EAP teleconnection in Fig 1 (a), indicating that the EAP teleconnection has a deep vertical structure. The regressed zonal section of geopotential

223 height onto the first principle component (PC1) of Fig. 1 (b) is presented in Fig. 2(b). The zonal

224 cross-section along $40^{\circ} \mathrm{E}$ exhibits an obvious wave train structure with negative and positive anomalies aligned with the Asian jet waveguide. Two negative anomalies, with maximum amplitude observed around $30^{\circ} \mathrm{E}-60^{\circ} \mathrm{E}$ and $90^{\circ} \mathrm{E}-120^{\circ} \mathrm{E}$, exhibit deep vertical structure tilting

227 westward in the whole troposphere, while anomalous wave patterns within $60^{\circ}-90^{\circ} \mathrm{E}$ are restricted mainly in the middle and upper troposphere. Statistically, significantly correlated regions also identify that this anomalous phase pattern is consistent with an eastward-propagating Rossby wave activity, suggesting that the SR teleconnection has the vertical structure. The stable vertical

231 structures of EAP and SR teleconnection, which are consistent with previous studies (Lu 2004,

232 Hsu \& Lin 2007, Kosaka et al. 2009), may cause certain co-action to the summertime atmospheric 

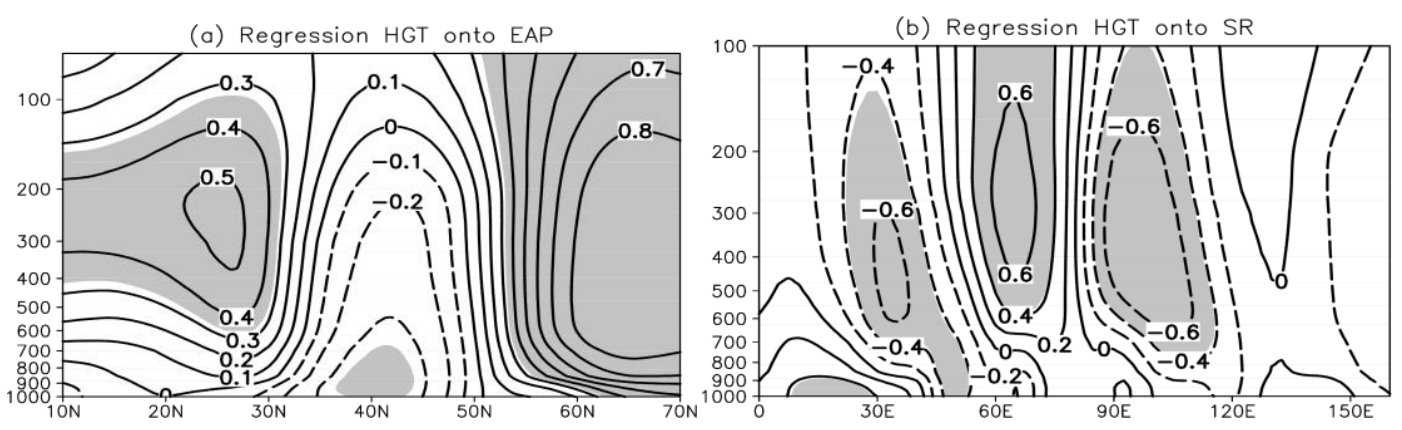

FIG. 2. (a) Meridional cross section of geopotential anomalies along $120{ }^{\circ} \mathrm{E}$ regressed onto the

PC1 of Fig. 1 (a) and zonal cross section of geopotential anomalies along $40{ }^{\circ} \mathrm{N}$ regressed onto the

PC1 of Fig. 1 (b). Shaded areas indicate the 95\% significance level.

In order to study the relationship between EAP and SR teleconnection (Huang 2004, Hsu \& Lin

2007), indices of EAP teleconnection and SR teleconnection are defined by using the formula (1)

and (2) in section 2, respectively. Fig 3 (a) shows composite differences of summer precipitation

anomalies between five low-value years and five high-value years of EAP index. Negative precipitation anomalies with significant positive CCs distributed in tropical region $\left(10^{\circ} \mathrm{N}-25^{\circ} \mathrm{N}\right)$ and extratropical region $\left(50^{\circ} \mathrm{N}-70^{\circ} \mathrm{N}\right)$, while positive precipitation anomalies with significant negative CCs dominate the subtropical region $\left(30^{\circ} \mathrm{N}-45^{\circ} \mathrm{N}\right)$ along the rainfall band from central

East China to the Korean Peninsula, Japan and its maritime region. The spatial distribution of correlation between EAP and summer precipitation in EA-WP implies the similar meridional tripole pattern from low latitude areas to high latitude regions as EAP teleconnection. Composite differences of summer precipitation anomalies for SR index has an obvious zonal pattern along the $40^{\circ} \mathrm{E}$ longitude (Fig $3 \mathrm{~b}$ ). Negative anomalies with positive CCs dominate central East China, 
(a) Composite CMAP EAP
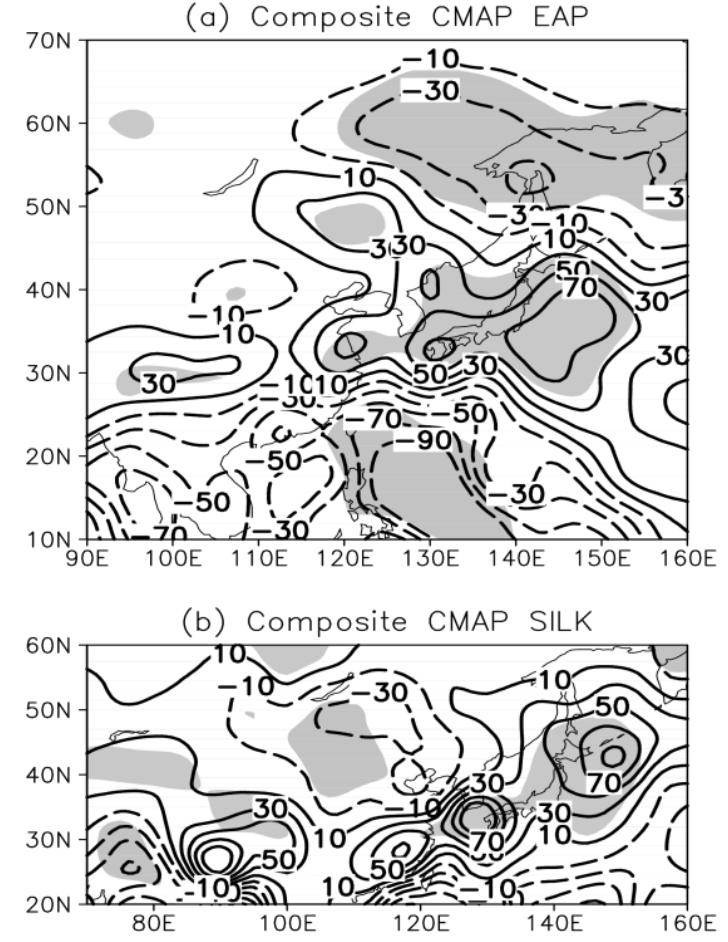

FIG. 3. Composited differences of summer precipitation anomalies (Units, $\mathrm{mm}$ ) between five coefficients below the $95 \%$ significance level are not plotted.

Fig. 4 (a) presents the time series of EAP and SR indices, both are dominated by the interannual variation. Based on the two series, scatter distribution of EAP and SR (Fig. 4 b) shows four patterns of EAP-SR composition, with anomalous phases as pattern I (positive EAP- positive SR, ++ ), pattern II (negative EAP - positive SR, - +), pattern III (negative EAP - negative SR, - -) and pattern IV (positive EAP - negative SR, + -), respectively. Table 2 presents corresponding years of different EAP-SR composition patterns. Year numbers for EAP-SR patterns vary from six to 

in EA-WP.
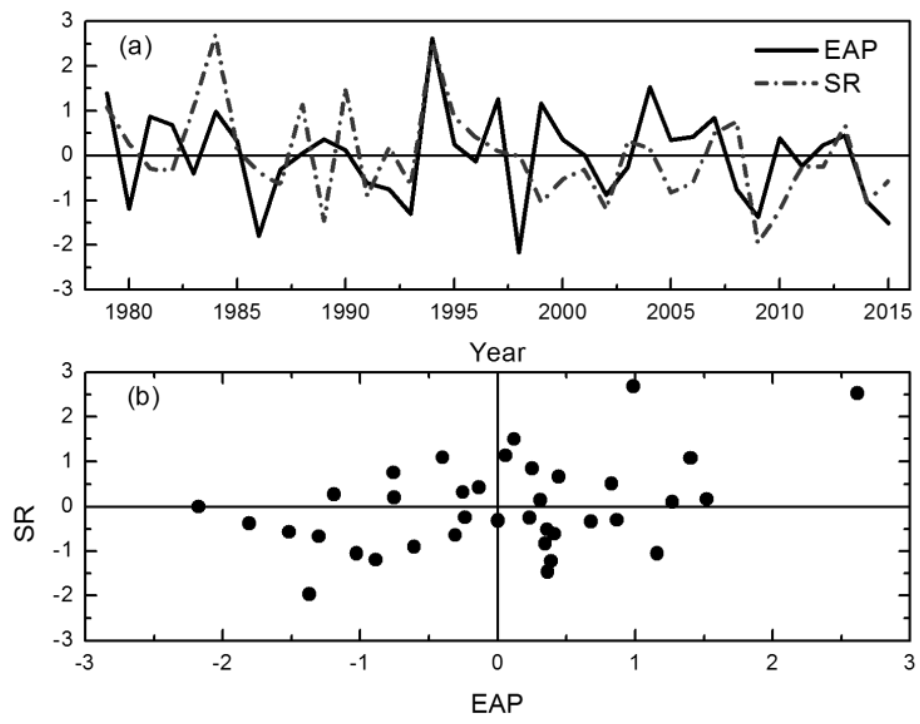

FIG. 4. EAP and SR curves (a) and scatter diagram indicating yearly distribution of EAP index and SR index (b).

Table 2. Years corresponding to different EAP-SR composition patterns.

\begin{tabular}{|ll|}
\hline EAP-SR & Years \\
\hline Pattern I (++) & $1979,1984,1985,1988,1990,1994,1995,1997,2004,2007,2013$ \\
\hline Pattern II (- +) & $1980,1983,1992,1996,2003,2008$ \\
\hline Pattern III (- -) & $1986,1987,1991,1993,1998,2002,2009,2011,2014,2015$ \\
\hline Pattern IV (+ -) & $1981,1982,1989,1999,2000,2001,2005,2006,2010,2012$ \\
\hline
\end{tabular}

278 Note, "+" denotes positive index value, "-" denotes negative index value. Pattern I "+ +" denotes the EAP-SR composition with positive EAP index and positive SR index. Other three patterns 
have corresponding definitions as pattern I.

Both EAP and SR teleconnections have obvious effect on the summer precipitation in EA-WP, which replace the westward expansion/eastward retreat of the PASH (Lu \& Lin 2009, Kosaka et al. 2012) then influence moisture transported from the subtropics to the extratropics (Huang et al. 2007). Four patterns of summer precipitation anomalies and 500-hPa geopotential height anomalies corresponding to different EAP-SR compositions are exhibited in Fig. 5 and Fig. 6, respectively. Values larger than 0.5 standard deviations for both EAP and SR indices are selected to perform the composite analysis for Pattern I (III). Values larger than 0.3 standard deviations are selected for Pattern II (Saha et al.) because years belong to these two patterns are less than the other two. Accordingly, five years $(1979,1984,1994,2007$, and 2013) for pattern I, four years (1980, 1983, 2003, and 2008) for pattern II, five years (1991, 1993, 2002, 2009, and 2014) for pattern III and seven years $(1982,1989,1999,2000,2005,2006,2010)$ for pattern IV are selected respectively for composite analysis. For the pattern I, when summer precipitation is above normal in the tropical and extratropical region (Fig. 5a), negative anomalies of geopotential height at 500-hPa are obvious over the low latitude regions and high latitude regions of eastern EA-WP (Fig. 6a). Precipitation anomalies show west-east opposite phase over the subtropical region (Fig. 5a) accompanied by the positive-negative-positive wave like pattern from west to east along the $40^{\circ} \mathrm{N}$ zonal belt at 500-hPa geopotential height anomalies (Fig. 6a). For pattern II, summer precipitation anomalies show a tripole pattern with negative anomalies located in the tropical and extratropical regions and with positive anomalies distributed in the subtropical regions from west to east (Fig. 5b). Correspondingly, geopotential height anomalies at 500-hPa show the tripole pattern in 
302

303

meridional direction over EA-WP, while the west-positive east-negative pattern is replaced by the consistent negative anomalies along the band from lower reaches of the Yangtze river to Japan and the East regions (Fig. 6b). Composite differences of summer precipitation for pattern III - pattern I (Fig. 5c) have the similar spatial structure, but converse phase distribution of pattern I. Geopotential height anomalies in Fig. 6(c) correspondingly present the triple meridional structure along the band from North China to Japan, and exhibit a negative-positive-negative wave train from west to east along the $40^{\circ} \mathrm{N}$ zonal band over the subtropical regions. Composite differences of summer precipitation (Fig. 5d) and geopotential height (Fig. 6d) for pattern IV - pattern II exhibit a similar spatial structure of pattern II, but with converse phases anomalies. The summer precipitation composition modes of Pattern III and pattern IV show significant correlation with the modes of pattern I and II, with the spatial CCs are respectively -0.59 and -0.33 , both passing the 99\% significance level. That is to say, pattern III (Saha et al.) have the similar spatial structure but converse phase anomaly as pattern I (Ishii et al.).

Since four EAP-SR patterns are not totally independent from each other, the fraction variance percentage $\left(\operatorname{Var}_{i, j}\right)$ of each grid point is calculated as formula (5)

$$
\operatorname{Var}_{i, j}=\frac{\sum_{k=1}^{N}\left(R_{k}-\bar{R}\right)^{2}}{\sum_{l=1}^{M}\left(R_{l}-\bar{R}\right)^{2}} \times 100 \% \quad(k=1,2,3, \ldots N ; \quad l=1,2,3, \ldots, M)
$$

where, $R_{k}$ is the precipitation at each grid point, $\bar{R}$ is the average precipitation for 1991-2015, $l$ denotes the EAP-SR pattern, $N$ is the number of years for each composition pattern, $M$ is the total number of years from 1991 to 2015 . The percentage variance for each pattern, $\left(\operatorname{Var}_{L}, L=\right.$ $I, I I, I I I$, and $I V)$, is calculated as the average for all the grid points within the region $\left(10^{\circ} \mathrm{N}-70^{\circ} \mathrm{N}\right.$, $\left.90^{\circ} \mathrm{E}-160^{\circ} \mathrm{E}\right)$. Percentage variance of summer precipitation explained by each of the four patterns 

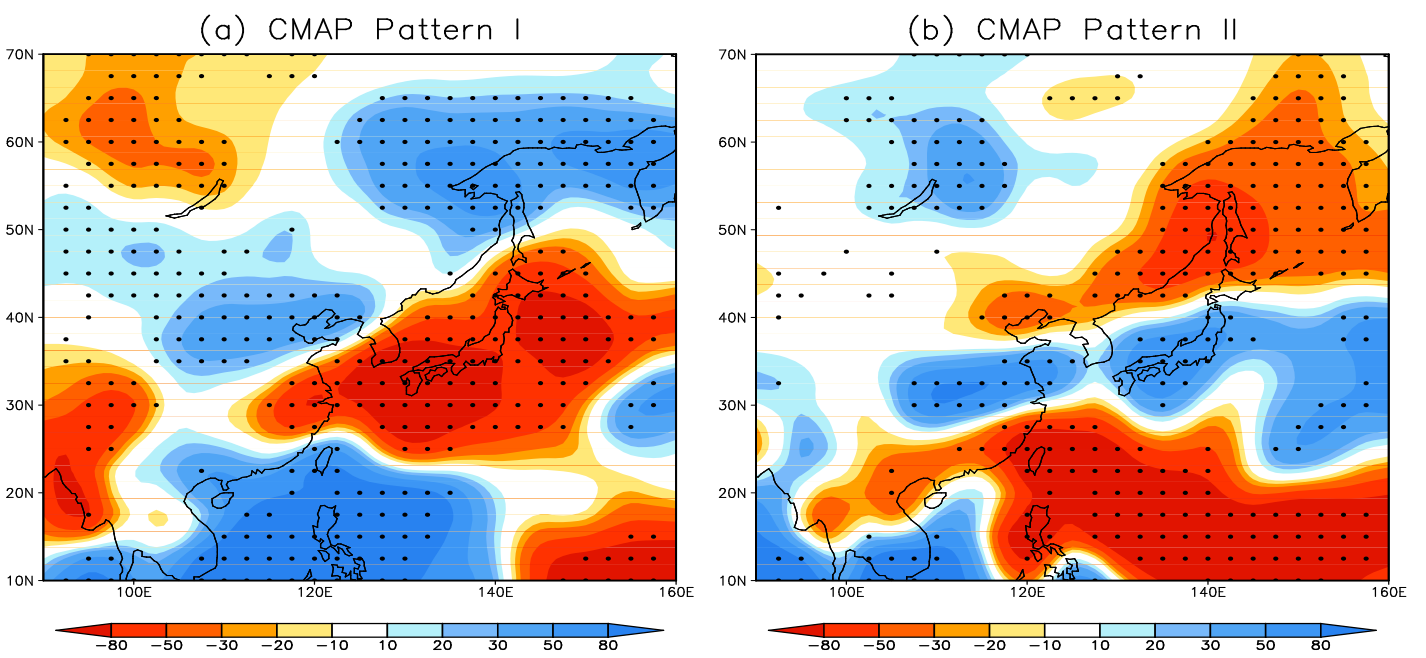

(c) CMAP Pattern III - Pattern I

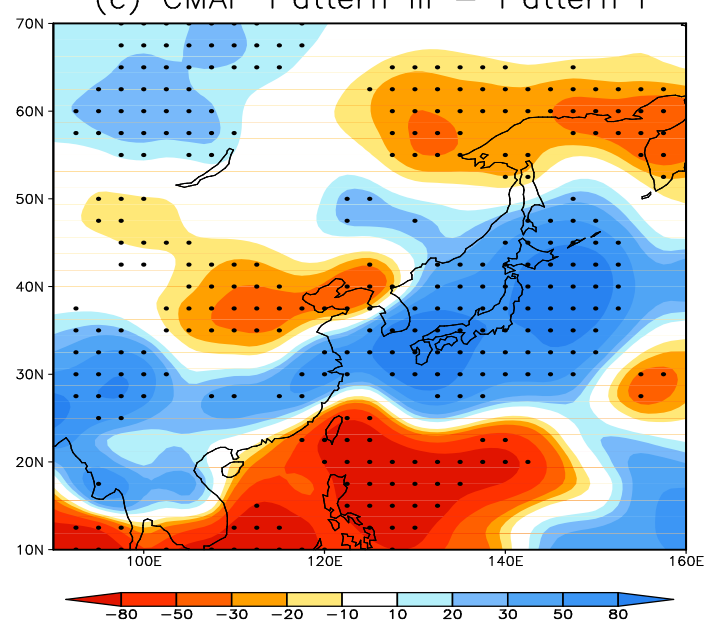

(d) CMAP Pattern IV - Pattern II

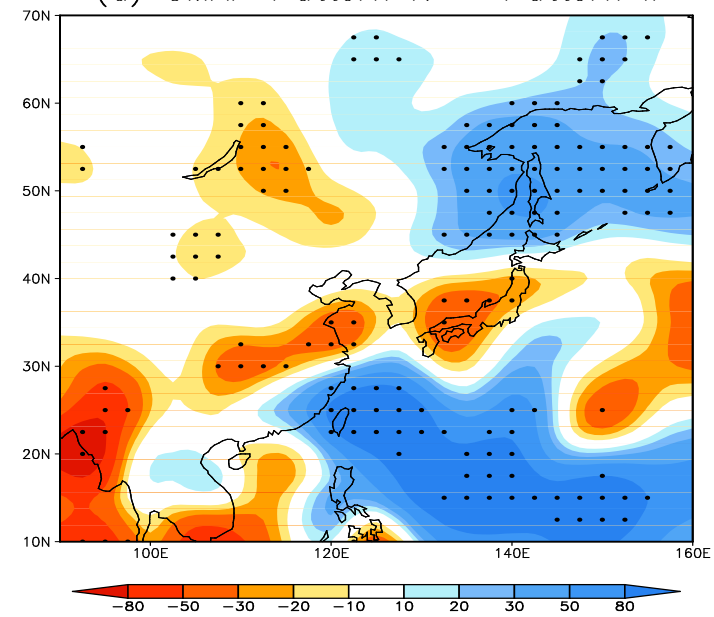

FIG. 5. Composited abnormal (units: $\mathrm{mm}$ ) of summer precipitation for pattern I (a) and Pattern II

(b) of EAP-SR composition; Differences of composited abnormal (units: mm) for (c) Pattern III -

Pattern I, (d) Pattern IV - Pattern II. Dotted areas indicate the 95\% significance level. 
(a) Z500 Pattern ।

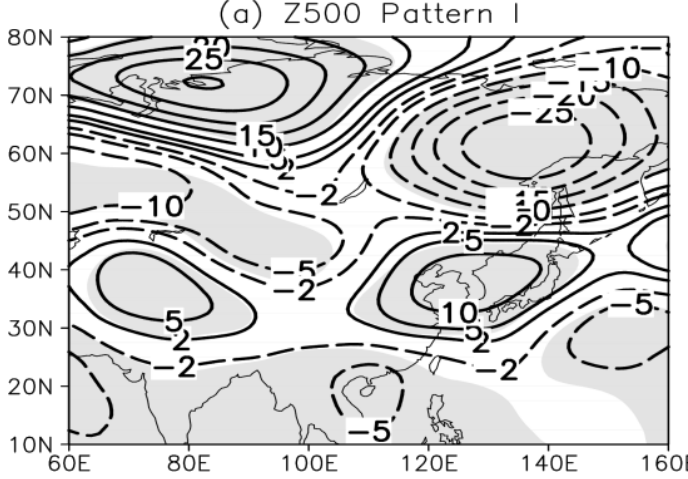

(c) Z500 Pattern III - Pattern I

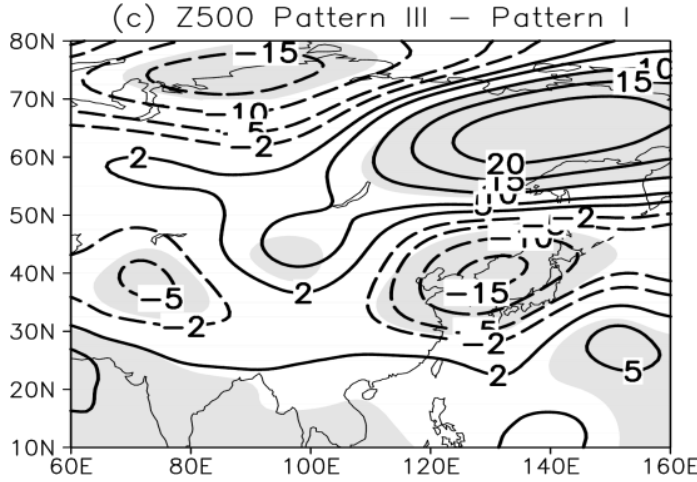

(b) Z500 Pattern II

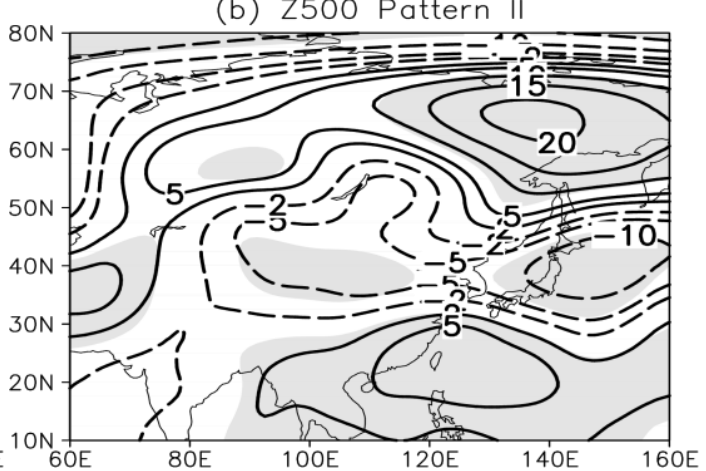

(d) Z500 Pattern IV - Pattern II

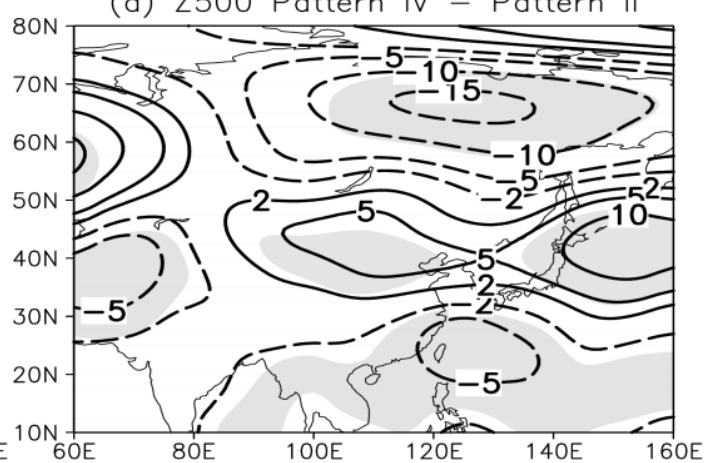

FIG. 6. Same as Fig. 5 but for composite anomalies of summer geopotential height (units: gpm) at 
348 I and pattern II of EAP-SR compositions (Fig. 8 a, c). Continuous negative (positive) anomalies in

349 the zonal direction dominate the subtropical region for pattern II and pattern IV (Fig. 8 b, d).

350 Zonal cross-sections of vertical geopotential height anomalies averaged between $120^{\circ} \mathrm{E}$ and $130^{\circ} \mathrm{E}$

351 (Fig. $8 \mathrm{e}-\mathrm{h}$ ), demonstrate consistent tripole patterns between $30^{\circ} \mathrm{N}$ and $60^{\circ} \mathrm{N}$, reflect that the

352 anomalies over the subtropical region for pattern II (Saha et al.) are much weaker compared with pattern I (III).
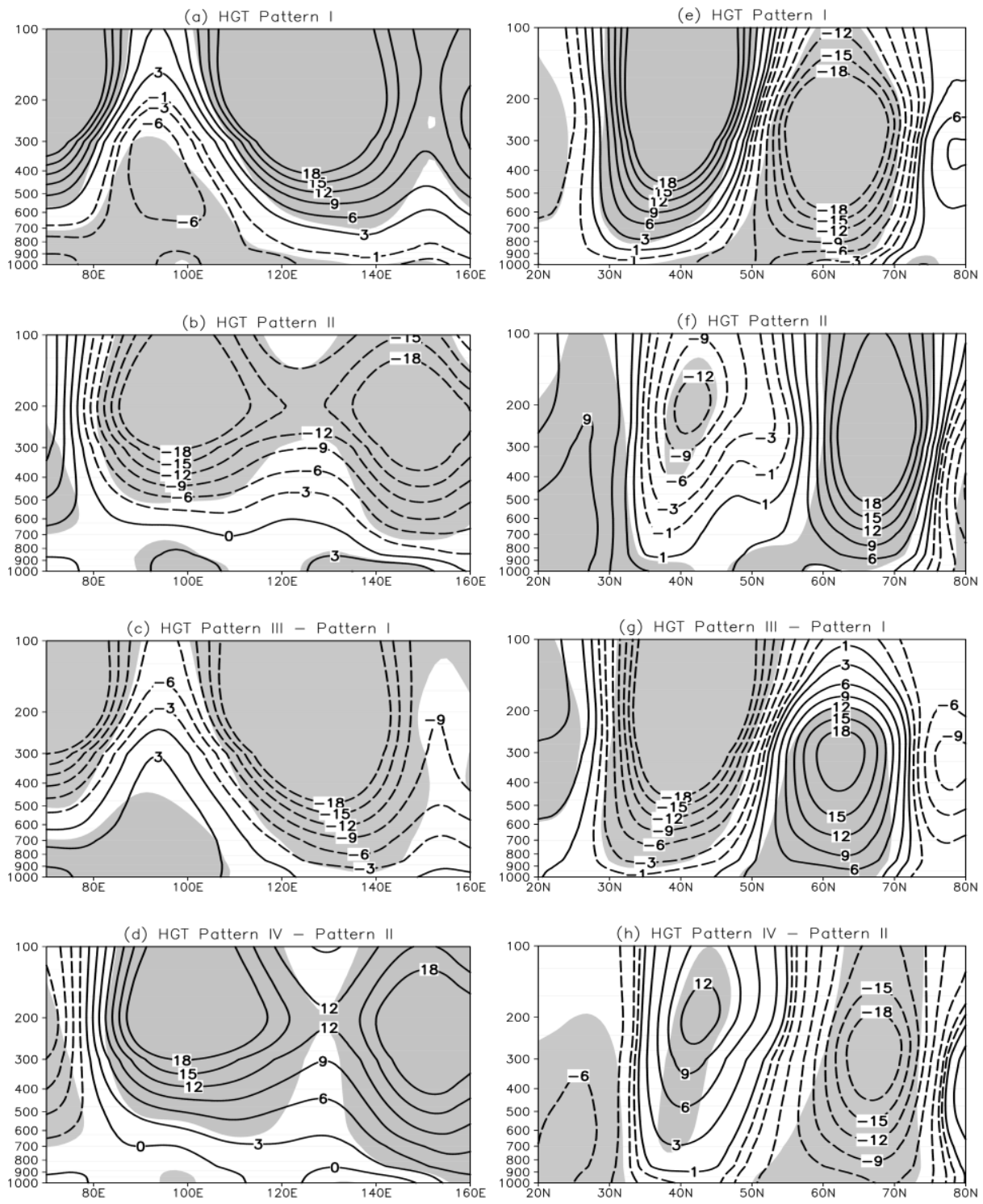
358

359

360

361

362

363

364

FIG. 8. Same as Fig. 5 but for the meridional cross-sections of geopotential (contour, gpm) along $40^{\circ} \mathrm{N}(\mathrm{a})-(\mathrm{d})$ and zonal cross-sections of average between $120^{\circ} \mathrm{E}-130^{\circ} \mathrm{E}(\mathrm{e}-\mathrm{h})$ from $1000-\mathrm{hPa}$ to 100-hPa. Shadings indicate the $95 \%$ significance level.

Anomalies of 500-hPa wind vectors and integrated moisture divergence for EAP-SR patterns are presented in Fig. 9. For pattern I (Fig. 9 a), wind anomalies at the middle troposphere (500-hPa) feature anomalous cyclones (anticyclone) over the tropical and the extratropical region (the subtropical region). These conditions, owing to the correlation of summer precipitation anomaly pattern with the anomalies of wind vectors and the moisture convergence (divergence) (Lu et al. 2006, Lu \& Lin 2009, Xu et al. 2015), result in positive (negative) precipitation anomalies over the tropical and the extratropical regions (the subtropical region) of eastern EA-WP. Meanwhile, an anticyclone-cyclone-anticyclone-cyclone coupled wave train features the subtropical region from west to east. The significant cyclone (anticyclone) over the West China (the North China-Japan region) leads to positive (negative) precipitation anomalies in North China (Japan and its maritime region). Composite differences of wind vectors and moisture divergence for pattern III - pattern I presented in Fig. 9 (c) reflect that pattern III has the opposite spatial phase characteristics compared to pattern I. Meanwhile, for pattern II (Fig. 9 b), wind vectors feature an anomalous anticyclone-cyclone-anticyclone meridional tripole pattern in the meridional direction, leading to the tripole anomalous precipitation distribution. The pattern I's wave train over the subtropical region (Fig. 9a) is replaced by two cyclones controlling the western and eastern portions of the subtropical regions, which causes a positive precipitation band from the Yangtze River Basin to Japan. Fig. 9 (d) reflects that wind vectors and moisture divergence for 

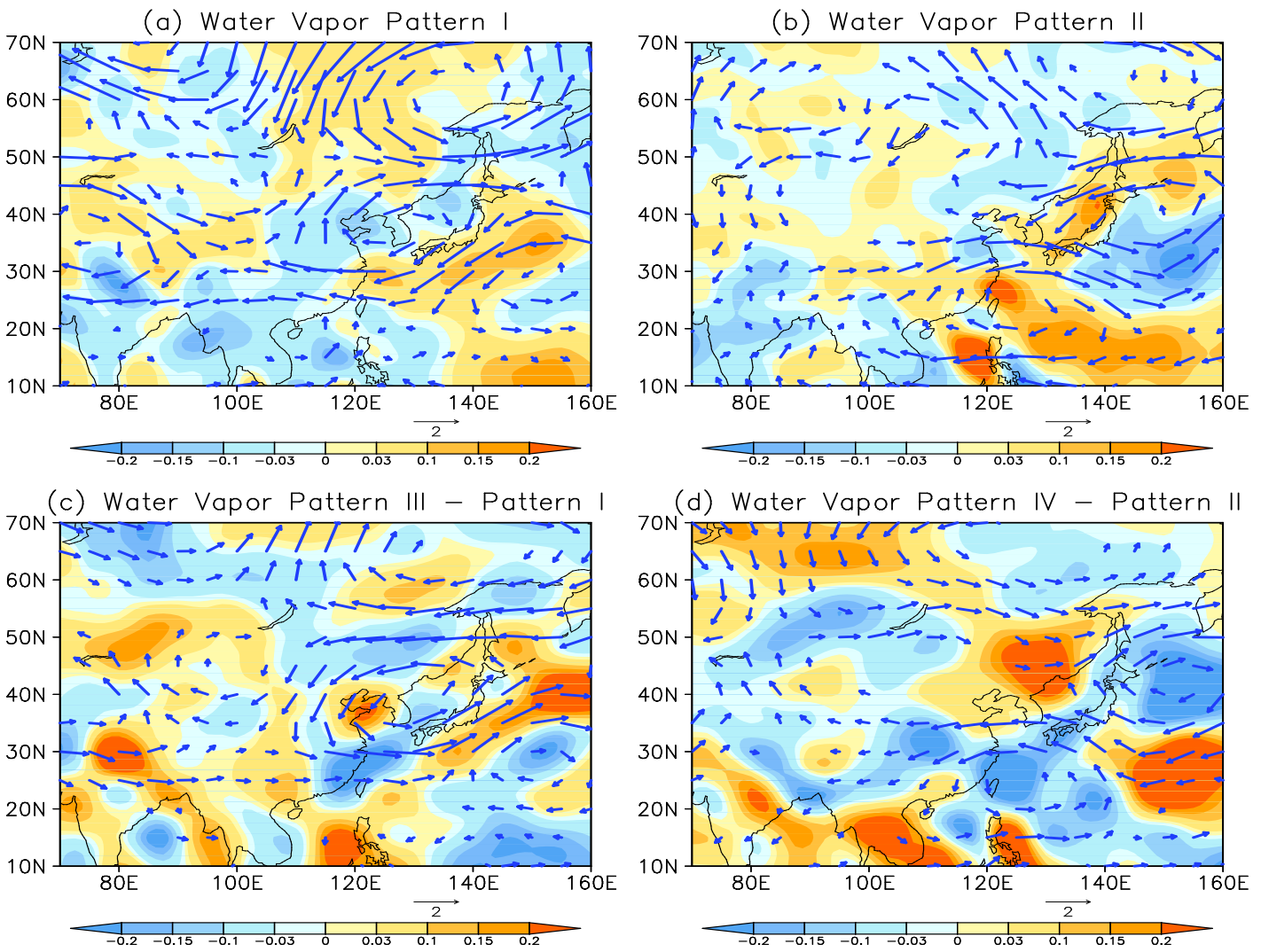

FIG. 9. Same as Fig.5 but for divergence of integrated moisture from the surface to $200 \mathrm{hPa}$

(shading, $10^{-5} \mathrm{~kg} \mathrm{~m}^{-2} \mathrm{~s}^{-1}$ ) and wind anomalies (vector, $\mathrm{ms}^{-1}$ ) at $500 \mathrm{hPa}$. Only wind vectors above

the $95 \%$ significance level are plotted.

Figs. 10 (a) and (b) are distributions of CCs of summer geopotential height anomalies with index 
and (d). Pattern I of EAP-SR composition with positive-positive indices have a "+ - +" anomaly structure from west to east in the zonal direction and "- + -" anomaly structure from south to north in the meridional direction. The overlapped positive anomalies in the subtropical region may strengthen the negative-positive anomalous phase contrast between the lobe east of and the lobe west of $120^{\circ} \mathrm{E}$, and also strengthen the tripole anomalous structure in the meridional direction (Fig. $10 \mathrm{c})$, leading to the geopotential height pattern exhibited in Fig. 6 (a). Pattern III of EAP-SR composition with negative - negative indices has a similar explanation of pattern I. Figure 10 (d) shows pattern IV of EAP-SR composition with positive-negative indices, implying that the positive anomalous lobe of EAP in the subtropical region overlaps with the negative anomalous lobe of SR in the same region, which may weaken negative anomalies of SR and lead to the weak positive anomalies. Therefore, phase characteristics present two positive lobes in the zonal direction of the subtropical region (Fig. 6b). Meanwhile, negative lobes over extratropical and tropical regions respectively expand southward and northward, compressing the lobe over the subtropical region, causing the narrow and weak band of geopotential height anomalies. Pattern IV of EAP-SR composition shown in Fig. 6 (d) can be explained with the similar mechanism as of pattern II.
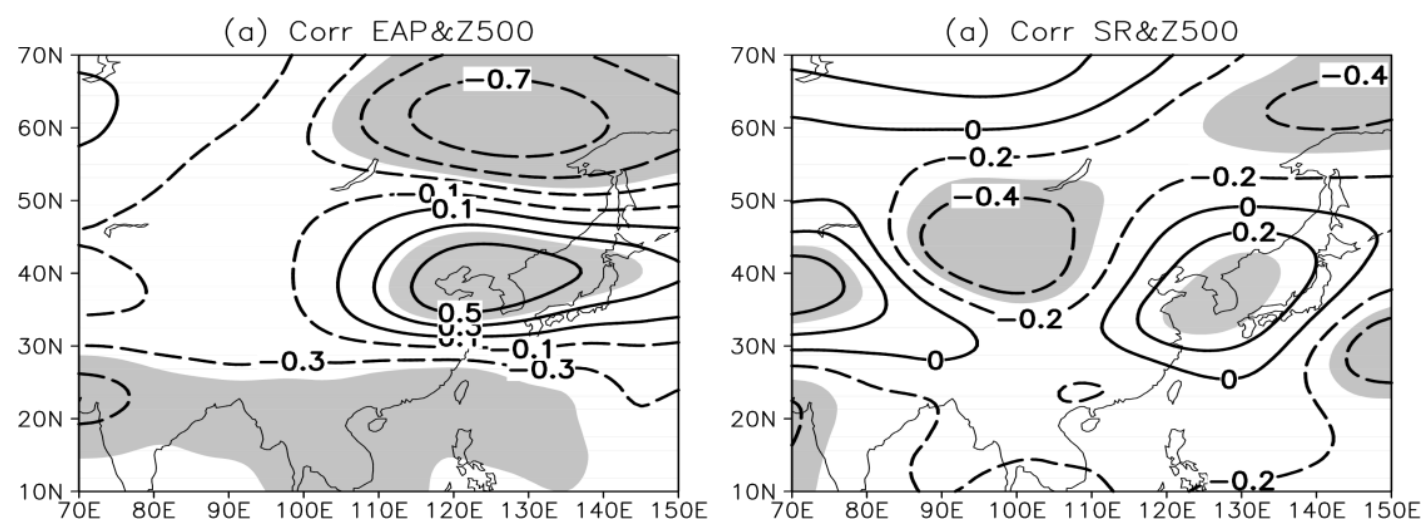
(c) Same phase

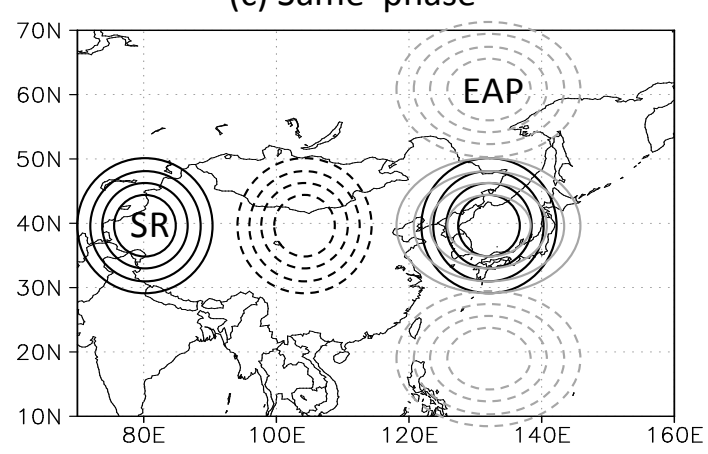

(d) Opposite phase

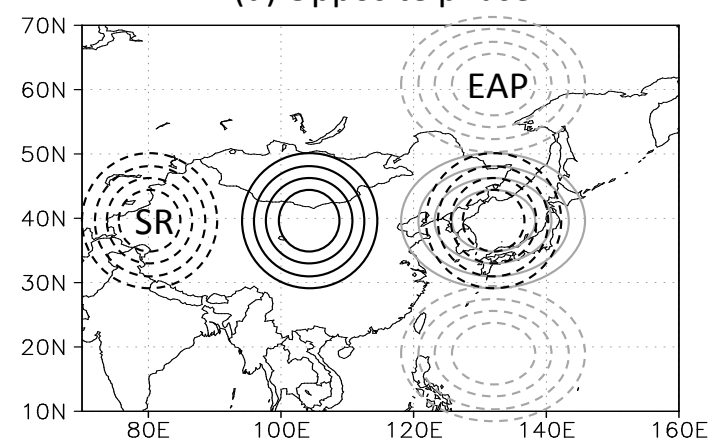

413

414

415

FIG. 10. Spatial distribution of CCs of geopotential height anomalies at 500-hPa with (a) EAP and

(b) SR and the schematic diagram of the combination of EAP and SR teleconnections at 500-hPa

with (c) same phase and (d) opposite phase. Shadings in (a) and (b) indicate the $95 \%$ significance level. For the schematic diagrams, black lines and gray contours represent the EAP and SR teleconnection, respectively, while straight contours indicate positive anomalies and dash contours indicate negative anomalies.

4. The physical dynamics causes for EAP-SR compositions

4.1 The physical dynamics process of EAP teleconnection

The tropical western Pacific has the highest Sea Surface Temperatures (SSTs) around the global sea surface. Due to the dominant thermal states of this region, SSTs of the tropical West Pacific play an important role in triggering strong convective activity and convergence of air and moisture around the Philippines (Cornejo-Garrido \& Stone 1977, Huang 1987, Nitta 1987, Ding 2007). Many studies (Kosaka \& Nakamura 2006, Li et al. 2008) also show that EAP teleconnections are caused by the heating anomaly due to thermal anomalies of the tropical West Pacific, or by convective activity anomalies around Indonesia. The time series of the SST average for the Indonesia maritime continent (IMC, Indonesia surrounding seas, $5^{\circ} \mathrm{S}-5^{\circ} \mathrm{N}, 100^{\circ} \mathrm{E}-130^{\circ} \mathrm{E}$ ), within which SST anomalies are negatively correlated with the EAP index (Figs. not shown), is 
431

432

433

434

435

436

437

calculated.

Regression anomalies of Outgoing Long Radiation (OLR) in Fig. 11 (a) indicate that negative OLR dominates the tropical West Pacific, which may cause the anomalous convective heating and trigger the corresponding enhanced convective activity in this area. This enhanced convective activity causes an anomalous upward motion (Fig. 11b) and results in the cyclonic wind vector and positive vorticity anomalies at 850 -hPa (Fig. 11c), and vice versa (Kosaka \& Nakamura 2006). Meanwhile, positive OLR, downward motion, anticyclonic wind vector, and negative vorticity anomalies are observed over the South China Sea, which indicates that the positive geopotential height anomalies may dominate over this region. Meanwhile, negative OLR anomalies are observed around Japan and its maritime region (Fig. 11a), corresponding to enhanced convective activity (Fig. 11b) and positive geopotential height anomalies at 500-hPa. Corresponding to the significant meridional components, coupled vertical motions and horizontal wind anomalies from tropical region to extratropical region could be seen in Fig. 11 (b) and (c), indicating the interaction between different components of the tripole wave pattern. The regressed summer precipitation presents the positive-negative-positive-negative spatial structure from the south to north (Fig. 11 d) which is consistent with the OLR distribution shown in Fig. 11 (a). Therefore, thermal activity caused by anomalies of SSTs over the tropical West Pacific, especially over the IMC, might be one of the external forces for triggering the EAP teleconnection. 
(a) OLR

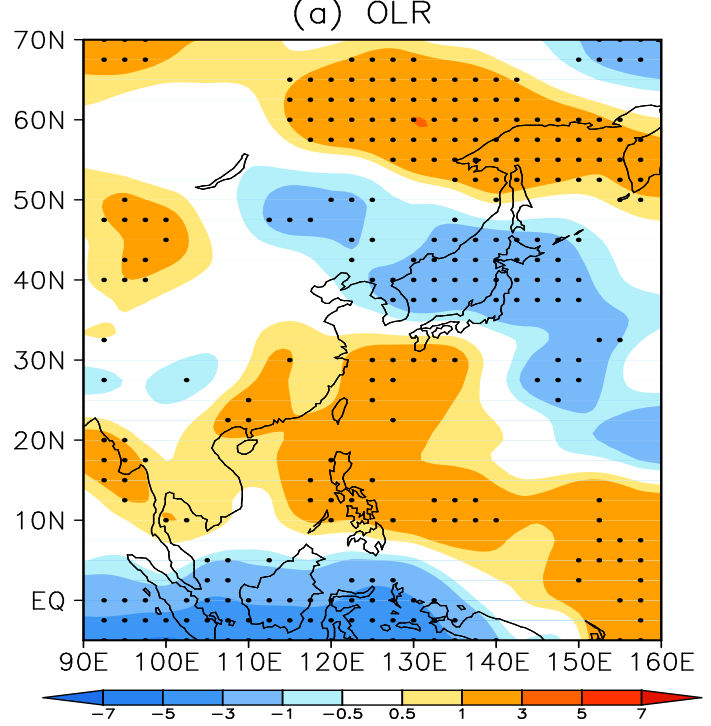

(b) Vorticity \& omega
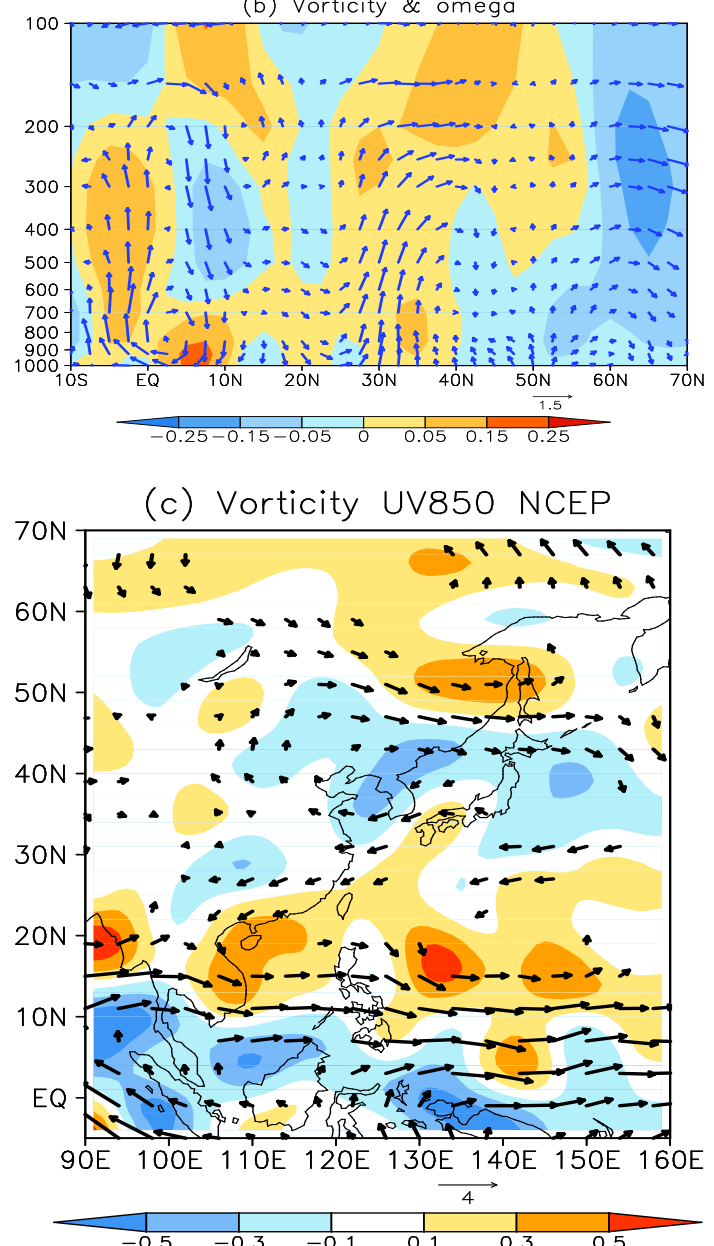


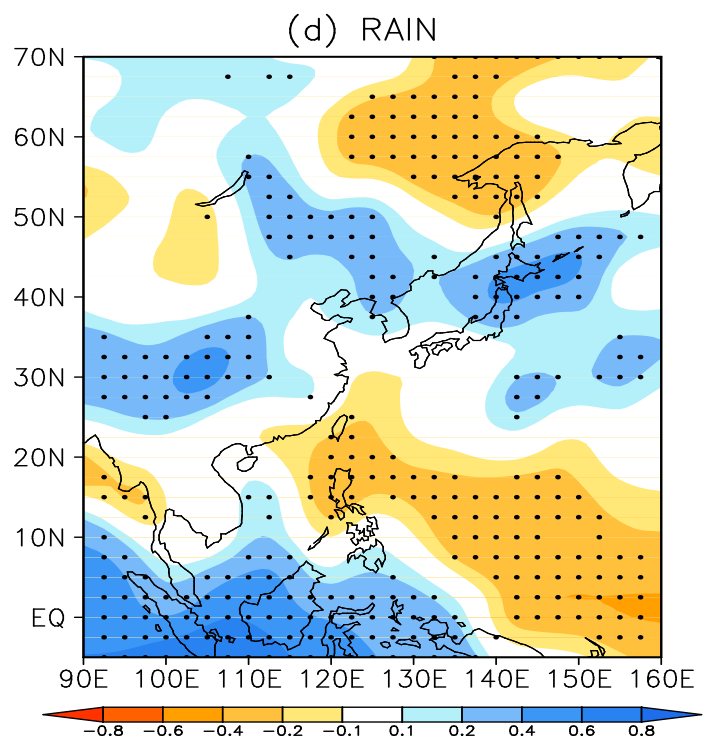

FIG. 11. Regression of anomalies of (a) OLR (units: $\mathrm{W} \mathrm{m}^{-2}$ ), (b) meridional cross-section of corresponding wind vector (units: $\mathrm{m} \mathrm{s}^{-1}$ ), (d) standardized summer precipitation onto the time from the IMC SST regressed OLR (Fig. 11 a) and precipitation pattern (Fig. 11 d), implying there 
471 also plays an important role in triggering the EAP pattern and influencing the relevant summer

472 precipitation structure. Furthermore, the OLR of pattern II (Fig 12 b) shows the wave train

473 structure in the meridional direction which is consistent with the IMC related OLR (Fig. 11 a) and

474 precipitation pattern (Fig. 11 d), indicating the IMC related precipitation anomaly is comparable to

475 the precipitation and OLR anomaly pattern. Accordingly, the remote tropical East SST forcing as

476 well as the local SST forcing are both key factors for producing the principle portion of summer

477 precipitation over EA-WP (Zhou et al. 2009).

478

479

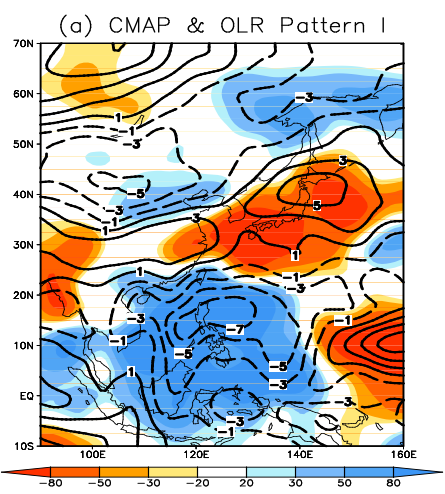

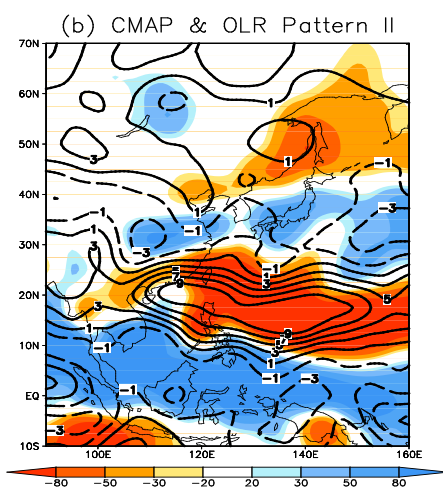

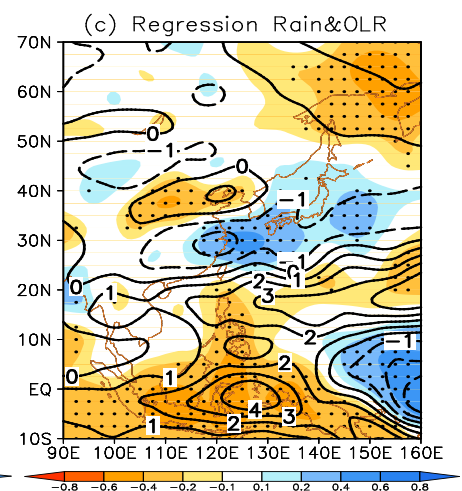

Fig. 12 Composite abnormal of summer precipitation (shading, units: mm) and OLR (contour,

level for the summer precipitation. 
this teleconnection may be due to the eastward propagation of the Rossby wave train along the westerly jet stream at 200-hPa. Kosaka et al. (2009) revealed that SR's extraction of available potential energy from the baroclinic Asian jet is highly efficient for its self-maintenance. Kosaka et al. (2012) further simulated that blocking developed over eastern Europe in 2010 was instrumental in triggering the SR teleconnection. Correlation between SR and meridional wind velocity anomalies at $200-\mathrm{hPa}$ is shown in Fig. 13(a). Significant correlation exhibits a wave pattern originating from Western Europe, extending to Japan along the Asian jet stream. The time series of the geopotential height anomalies averaged over the possible source of SR teleconnection in East Europe $\left(37.5^{\circ} \mathrm{N}-40.0^{\circ} \mathrm{N}, 60^{\circ} \mathrm{E}-62.5^{\circ} \mathrm{E}\right)$ is defined as the EUG index (EUGI). Meridional wind velocity anomalies regressed onto the EUGI (Fig. 13 b) present a wave train pattern along the Asian jet stream. Regressed geopotential height anomalies and vorticity anomalies at 200-hPa (Fig. 13 c) also show a similar wave train structure as the SR teleconnection.

It is also noted that a waveguide originating from Eastern Europe and propagates to Pakistan and northeastern India. According to a previous study (Ding \& Wang 2005), an anomalous high can be triggered over eastern Europe, causing a Rossby wave train propagation from western Europe to west-central Asia, resulting in an enhanced convection and precipitation over northwestern India and Pakistan. Fig. 14 indicates that the MJJ (May, June, and July) precipitation may trigger the positive geopotential height and negative vorticity anomalies over central East Asia. Fig 15. (a) and (b) show anomalies of Z200, vorticity, and meridional wind velocity at 200-hPa regressed onto the time series of the $\mathrm{Z} 200$ averaged over the central Asia $\left(37.5^{\circ} \mathrm{N}-40^{\circ} \mathrm{N}, 60^{\circ} \mathrm{E}-62.5^{\circ} \mathrm{E}\right)$, reflecting a wave pattern from West Asia to Japan. That is to say, strengthened Z200 over central 
MJJ precipitation over India and Pakistan could regress the wave train existed in the meridional and maintains the SR teleconnection downstream.
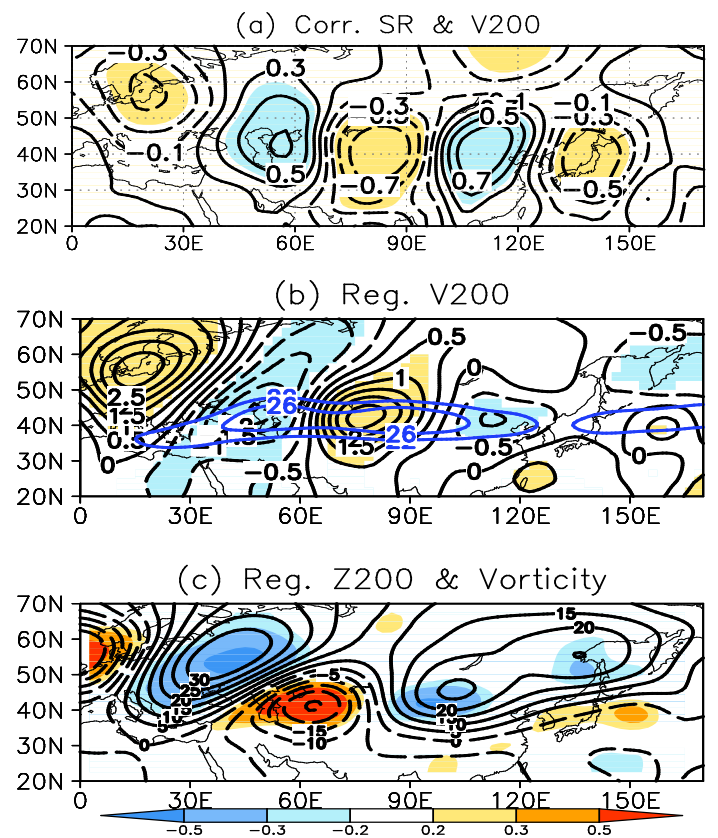

FIG. 13. Spatial distribution of (a) CCs of SR with meridional wind velocity anomalies, regression of (b) meridional wind velocity anomalies (contours, units: $\mathrm{m} \mathrm{s}^{-1}$ ), and vorticity anomalies (units: $\left.10^{-6} \mathrm{~s}^{-1}\right)$ \& geopotential height (gpm) at 200-hPa onto the EUGI index. Shadings in (a) and (b) indicate the $95 \%$ significance level. Green lines in (b) indicate the Asian jet; vectors of wave-activity flux below 0.5 in (c) are not plotted. 


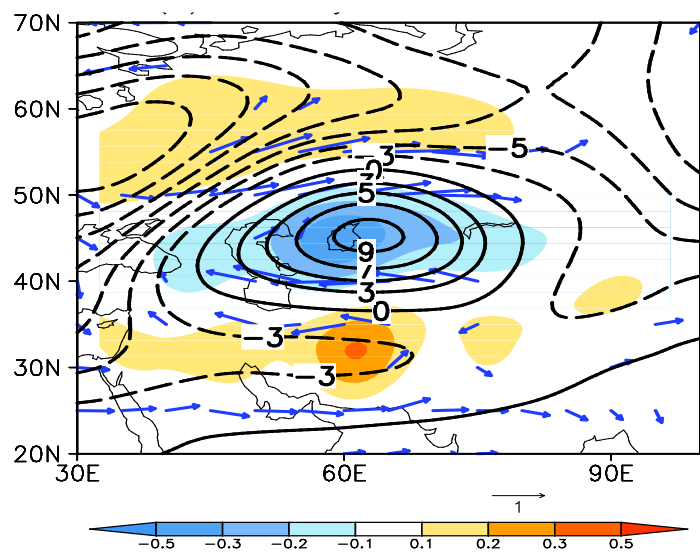

528 FIG. 14. Regression of summer (JJA) anomalies of Z200 (contour, units: gpm), vorticity (shading,

529 units: $\times 10^{6} \mathrm{~s}^{-1}$ ) and wind velocity (vector, $\mathrm{ms}^{-1}$ ) at $200-\mathrm{hPa}$ onto the time series of the precipitation

significance level are not plotted.

(a) Reg. Z200\&Vorticity onto Z200
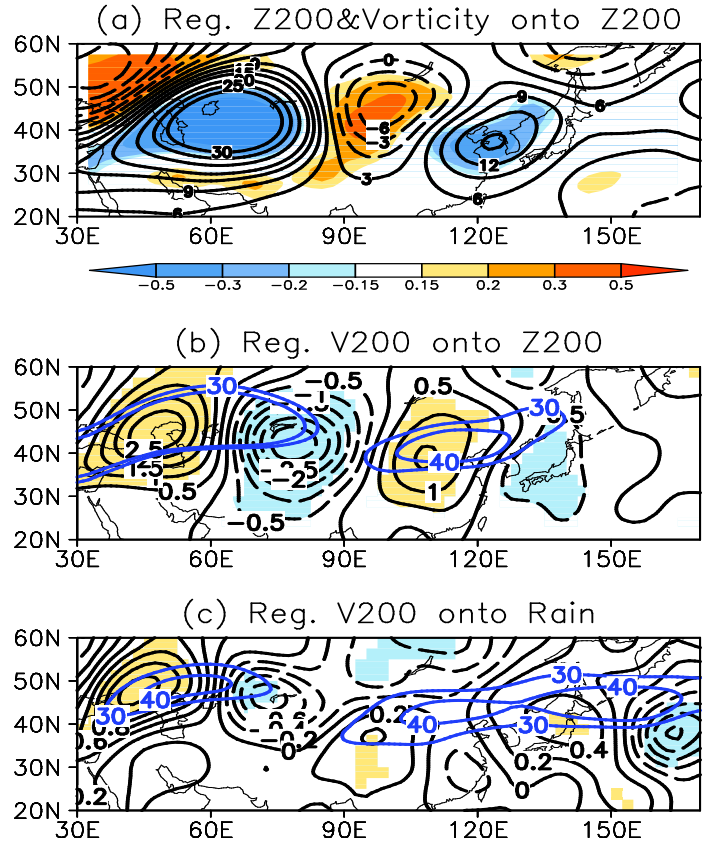

535 FIG. 15. Regression of anomalies of (a) Z200 (contour, units: ghm) and vorticity (shading, units:

$536 \times 10^{6} \mathrm{~s}^{-1}$ ), and (b) meridional wind velocity (contour, units, $\mathrm{ms}^{-1}$ ) at 200-hPa onto the time series of

537 the $\mathrm{Z} 200$ averaged over the region $\left(37.5^{\circ} \mathrm{N}-40^{\circ} \mathrm{N}, 60^{\circ} \mathrm{E}-62.5^{\circ} \mathrm{E}\right)$; (c) meridional wind velocity

538 (vector, $\left.\mathrm{ms}^{-1}\right)$ at $200 \mathrm{hPa}$ onto the time series of the precipitation average over the region $\left(18^{\circ} \mathrm{N}-\right.$

$\left.53930^{\circ} \mathrm{N}, 65^{\circ} \mathrm{E}-75^{\circ} \mathrm{E}\right)$. Green lines in (b) and (c) are 30 and $40 \mathrm{~ms}^{-1}$ of contours of the 
climatological-mean zonal wind velocity, which indicate the Asian jet waveguide. Vorticity below the $95 \%$ significance level in (a) are not plotted. Yellow and blue shadings indicate the positive and negative $95 \%$ significance level.

\section{SST anomaly and wave pattern corresponding to the EAP-SR composition}

Section 4 revealed that anomalies of tropical Pacific SST is the major external force for exciting the EAP teleconnection, while the internal atmospheric anomalies and wave-activity are the major reasons for motivating and maintaining the SR teleconnection. The SST anomaly and wave-activity pattern corresponding to EAP-SR compositions are presented in this section.

Fig. 16(a) shows the anomalies of SST corresponding to pattern I of EAP-SR composition, in which SCS, Bay of Bengal, the eastern tropical Indian Ocean and the tropical Pacific around the Philippines are dominated by negative SST anomalies. Meanwhile, negative SST is also observed in the tropical East Pacific. One the one side, as addressed in section 4.1, negative SST anomalies over IMC suppress the convective activity in the tropical region, causing the anomalous upward motion and negative geopotential height at 500-hPa over the South China Sea through function of the Hadley circulation, then result in a positive EAP teleconnection. On the other hand, negative SST over tropical East Pacific may cause the convective activity in West Pacific and strengthen the positive EAP and produce more precipitation in West Pacific (Fig. 12a). For pattern II of EAP-SR composition, positive SSTs anomalies over tropical East Pacific is not significant (Fig. 16b), indicating its tele-influence on West Pacific convection is weak. Meanwhile, SSTs over IMC are dominated by positive SST anomalies (Fig. 16b), which can strengthen the heat convection, 

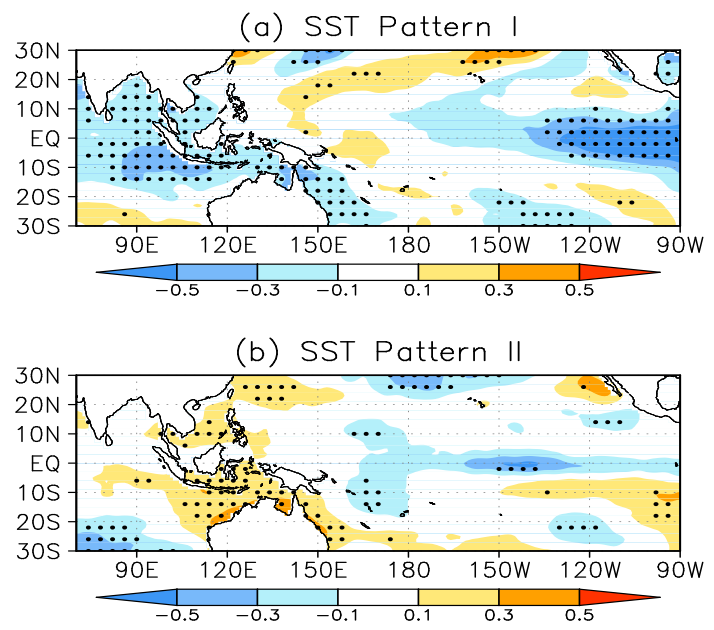

FIG. 16. Composite anomalies of SST (units: ${ }^{\circ} \mathrm{C}$ ) for (a) pattern I and (b) pattern II of EAP-SR

composition. Shadings indicate the $95 \%$ significance level.

Fig. 17(a) presents atmospheric anomalies and wave-activity flux of pattern I, in which eastern Europe is controlled by southward wind velocity anomalies and weak positive vorticity. Significant vorticity coupled with each other along the Asian jet stream, accompanied by eastward propagation of wave-activity fluxes, the meridional wind anomalies exhibit a "-+-+-" pattern at 200-hPa from eastern Europe to Japan (Kosaka et al. 2012). Meanwhile, atmospheric anomalies and wave-activity flux of pattern IV are presented in Fig. 17(b). Anomalies of meridional wind velocity and vorticity exhibit similar spatial structures but opposite anomalous phase of pattern I. 

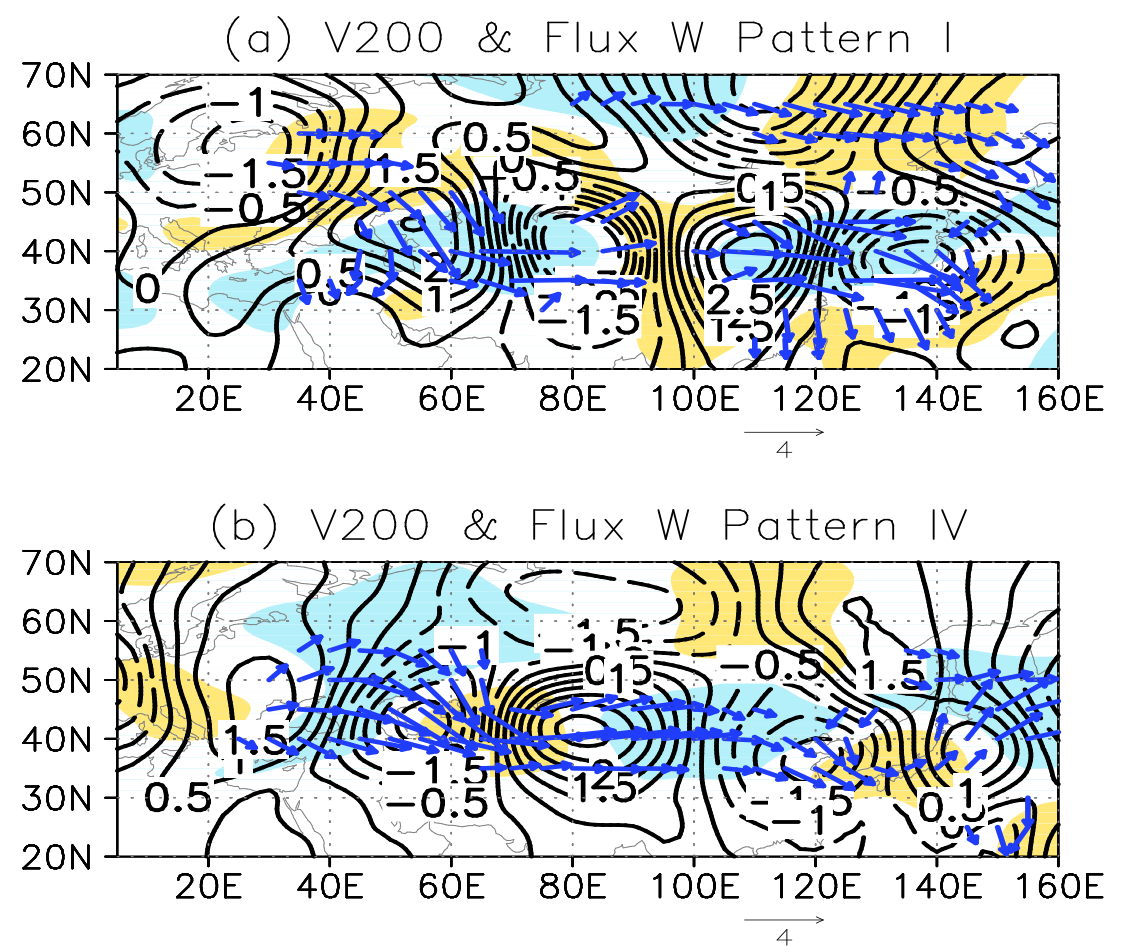

FIG. 17. Composite anomalies of summer meridional wind velocity (contours, units: $\mathrm{ms}^{-1}$ ), are not plotted.

EAP teleconnection has a close relationship with the meridional tripole pattern of summer precipitation over EA-WP, while SR teleconnection can affect the zonal anomalous wave pattern 
595

of summer precipitation along the Asian jet. Since origins of EAP and SR teleconnections are independent of each other (Huang 1987, Nitta 1987, Enomoto et al. 2003) and both teleconnections have influences on the climate of subtropical region, EAP-SR compositions are divided as pattern I $(++)$, pattern II $(+-)$, pattern III $(--)$, and pattern IV $(-+)$ based on EAP and SR indices for better understanding of the EAP-SR co-action on impacting climate anomalies in EA-WP.

\section{Spatial distribution of summer precipitation over EA-WP for pattern I (pattern III) shows tripole} meridional structure from low latitude to high latitude regions, with significantly positive (negative) anomalies over tropical and extratropical regions, and negative (positive) anomalies over subtropical regions. This meridional tripole pattern is more distinct in the region east of $120^{\circ} \mathrm{E}$ than west of that longitude. Zonal precipitation anomalies of pattern I (pattern III) present west - positive (negative) and east - negative (positive) structure in subtropical region. Meanwhile, summer precipitation of pattern II (Saha et al.) EAP-SR composition also exhibits tripole structure in meridional direction, while the zonal structure over subtropical regions presents narrow but continuous positive (negative) anomalies along the band between $30^{\circ} \mathrm{E}-40^{\circ} \mathrm{E}$.

Corresponding to the summer precipitation spatial anomalous distribution, geopotential height at 500-hPa shows the tripole meridional anomaly structure for pattern I (III) of EAP - SR composition, while the zonal anomalies along the Asian jet exhibit the "+-+" (-+-) wave pattern along the subtropical region from west to east. For pattern II (Saha et al.), the meridional anomalous pattern at $500-\mathrm{hP}$ has a similar tripole structure, while the zonal wave pattern is 

18.

replaced by the continuous negative (positive) anomalies over the subtropical region from the middle East China to Japan. Vertical sections of geopotential height anomalies further indicate that the EAP-SR composition maintain the atmospheric tripole anomalous patterns in the meridional direction. Besides, Pattern I (III) presents wave-like anomalous structure in the zonal direction over subtropical region of Eastern EA-WP, while pattern II (Saha et al.) exhibits continuous anomalies along the band around $40^{\circ} \mathrm{N}$, with the anomaly intensity over subtropical regions being much weakened and anomaly belt obviously compressed. It is implied that spatial distributions of geopotential height anomalies are consistent with the anomalous structure of summer precipitation in EA-WP. Moreover, spatial distribution of wind anomalies and moisture divergence (convergence) further demonstrate the possibility that summer precipitation patterns over EA-WP are caused by co-action of EAP and SR teleconnections.

The physical dynamical process of EAP teleconnection indicates that thermal activity caused by anomalies of SST over the Indonesia maritime continent is the external force for causing the EAP teleconnection. Meanwhile, atmospheric anomalies in the upper troposphere over eastern Europe might be the internal factor in causing wave train propagation to southward, triggering the precipitation over Pakistan and Northeastern India. The leading precipitation, in turn, will strengthens the anomalous high over west-central Asia that generates and maintains the teleconnection downstream of SR. Interpretation of the schematic mechanism for the co-action of EAP and SR teleconnection on influencing summer precipitation in EA-WP can be inferred in Fig. 
639

640

In Figure 18(a) of pattern I, negative anomalies of SST of IMC weakean the thermal convective activity, causing anomalous downward motion in equatorial region but upward motion over South China Sea. The upward motion triggers negative anomalies in the middle troposphere (500-hPa) over low latitude regions through the function of Hadley circulation. Besides, the negative SST over the tropical East Pacific may further cause the negative anomalies over the whole tropical West Pacific. Along with an equivalent barotropic structure tilting slightly northward, Rossby wave-like perturbations propagate northward in the lower and middle troposphere, causing positive anomalies at 500 -hPa over the subtropical regions. With the similar wave-activity propagating mechanism, negative anomalies dominate the high latitude region at 500-hPa. Meanwhile, in the zonal direction, positive anomalies at 500-hPa in Eastern Europe cause the wave-activity flux to propagate eastward along the Rossby wave train, which may also strengthen the precipitation over northeastern India and Pakistan. This situation causes the anomalous wave pattern "+-+-+" with positive SR teleconnection along the Asian jet stream at 500-hPa level. A positive SR-induced positive anomalies over the Korean Peninsula and Japan overlapped with the positive lobe of EAP teleconnection, which may strengthen the west-negative and east-positive contrast anomalies across $120^{\circ} \mathrm{E}$. Accordingly, pattern I of EAP-SR composition cause a meridional tripole pattern with more precipitation over low and high latitude regions, and less precipitation in subtropical regions in EA-WP. It also makes the zonal dipole pattern exhibit more precipitation over central East China, but less precipitation over the Korean Peninsula, Japan, and maritime region. In pattern II (Figure 18b), the positive SST anomalies over the tropical East Pacific is not significant, cause its tele-impact on the tropical West Pacific is very weak. Meanwhile, the negative anomalies of the IMC SST cause the negative EAP teleconnection. 
661

662

663

664

665

666

667

668

669

670

671

672

673

674

Corresponding negative anomalies over subtropical regions may weaken the positive SR-induced

positive anomalies over the Korean Peninsula and Japan, leading to the continuous negative anomalies at 500-hPa over subtropical regions from central East China to Japan. Accordingly,

more precipitation occurs over subtropical regions, while less precipitation exists over low latitude and high latitude regions in EA-WP. Pattern III of EAP-SR composition has a similar mechanism as Pattern I, while Pattern IV is similar to Pattern II (Figures are omitted).

(a) Positive EAP - Positive SR

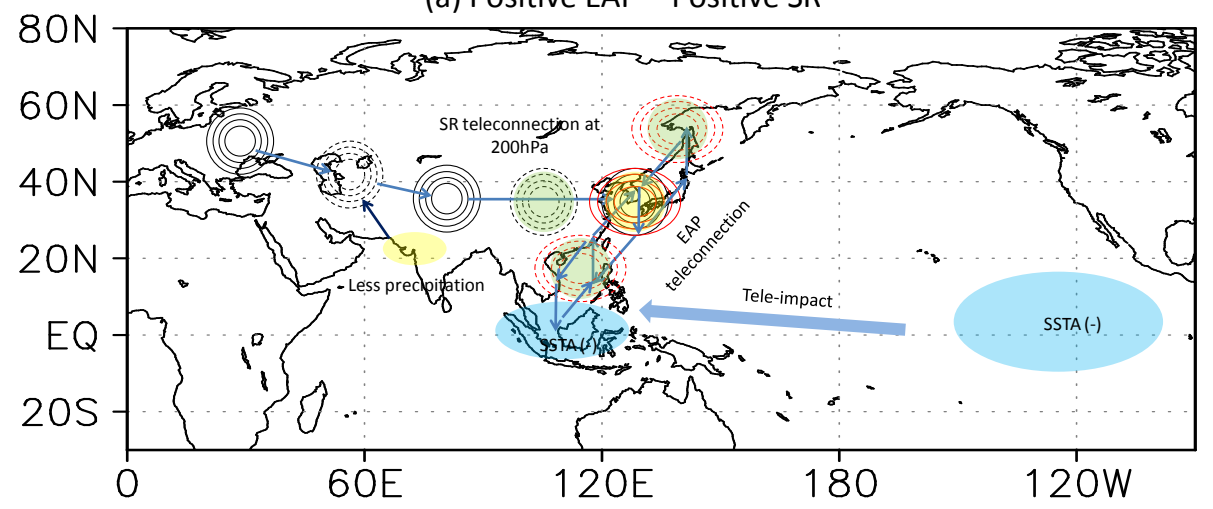

(b) Negative EAP - Positive SR

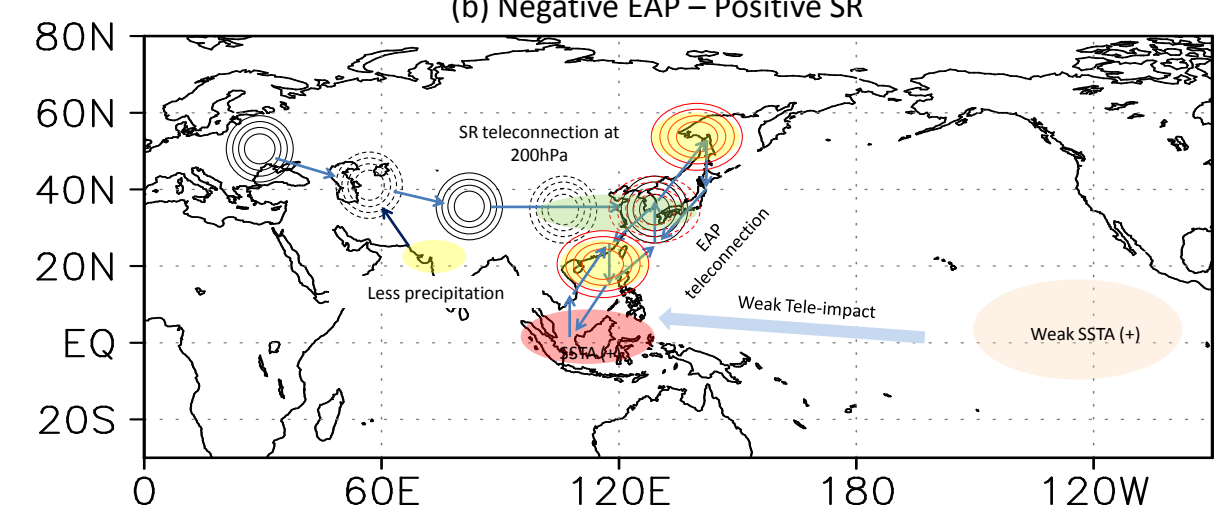

FIG. 18. Schematic diagram of the co-action of EAP and SR teleconnection on impacting the summer precipitation anomalous pattern over EA-WP. Black contours denote SR teleconnection at 200-hPa and red contours denote EAP teleconnection at 500-hPa. Arrows denote wave activity flux of Rossby wave train and vertical overturning circulation of EAP. Red shadings denote the positive SST anomaly, blue shading denotes the negative SST anomaly, green shadings denote more precipitation and yellow shadings denote less precipitation. 
675 Previous studies have also suggested that the mechanisms for triggering EAP teleconnection are diverse. For example, WPSH (Western Pacific Subtropical High) - ocean interaction can provide a source of climate predictability that extends ENSO impacts to upstream mid-latitudes, affecting the South Asian and EASM as a primary circulation system (Wang \& Fan 1994, Wang et al. 2013). The PJ pattern is the atmospheric manifestation of an air-sea coupled mode spanning the Indo-NWP warm pool. The PJ pattern forces the Indian Ocean (IO) via a westward propagating atmospheric Rossby wave. In response, IO SST feeds back and reinforces the PJ pattern via a tropospheric Kelvin wave. Ocean coupling increases both the amplitude and temporal persistence of the PJ pattern (Kosaka et al. 2013). The North-West Pacific anticyclone (NWP-AC) is embedded in a large-scale meridionally anti-symmetric Indo-Pacific atmospheric circulation response and has been shown to exhibit large impacts on precipitation in Asia (Stuecker et al. 2015). In this paper, we focused our attention on the role of tropical West Pacific SSTs heating anomalies in exciting the EAP teleconnection through the function of tropical Hadley circulation. Therefore, local SST-induced convection could be argued as one of the explanations to the physical dynamics forming the EAP teleconnection. This study further confirms the theory proposed by (Wang et al. 2009), in terms of the origins, there are two categories of summer precipitation modes in EA: ENSO related and non-ENSO (or weak ENSO) related.

\section{Acknowledgments. The authors wish to thank anonymous reviewers' meaningful comments that} led to a much-improved manuscript. Thanks also are extended to Dr. Pete Saunders for his great help in improving the writing of this manuscript. This work is supported by the National Natural Science Foundation of China (Grant Nos. 41575082, 41530531, and 41475064), the Special 
Scientific Research Project for Public Interest (Grant No. GYHY201306021).

\section{Reference}

Chen G, Huang R, Zhou L (2013) Baroclinic Instability of the Silk Road Pattern Induced by Thermal Damping. Journal of the Atmospheric Sciences 70:2875-2893

Cornejo-Garrido AG, Stone PH (1977) On the heat balance of the Walker circulation. Journal of the Atmospheric Sciences 34:1155-1162

Ding Q, Wang B, Wallace JM, Branstator G (2011) Tropical-Extratropical Teleconnections in Boreal Summer: Observed Interannual Variability. Journal of Climate 24:1878-1896

Ding QH, Wang B (2005) Circumglobal Teleconnection in the Northern Hemisphere Summer. J Climate 18:3483-3505

Ding Y (2007) The variability of the Asian summer monsoon. J Meteor Soc Japan 85:21-54

Ding YH, Chan JCL (2005) The East Asian summer monsoon: an overview. Meteorology and Atmospheric Physics 89:117-142

Dogar MM, Kucharski F, Azharuddin S (2017) Study of the global and regional climatic impacts of ENSO magnitude using SPEEDY AGCM. Journal of Earth System Science 126:30

Enomoto T, Hoskins BJ, Matsuda Y (2003) The formation mechanism of the Bonin high in August. Quarterly Journal of the Royal Meteorological Society 129:157-178

Feng G, Zhao J, Zhi R, Gong Z (2013) Recent progress on the objective and quantifiable forecast of summer precipitation based on dynamical statistical method. J Appl Meteor Sci 24:656-665

Gong ZQ, Feng GL, Ren FmM, Li JP (2013) A regional extreme low temperature event and its main atmospheric contributing factors. Theoretical and Applied Climatology 117:195-206

Gong ZQ, Feng TC, Fang YH (2015a) Objective identification research on cold vortex and mid-summer rainy periods in Northeast China. Chinese Physics B 24:049204

Gong ZQ, Hutin C, Feng GL (2016) Methods for Improving the Prediction Skill of Summer Precipitation over East Asia-West Pacific. Weather and Forecasting 31:1381-1392

Gong ZQ, Zhao JH, Feng GL, Chou JF (2015b) Dynamic-statistics combined forecast scheme based on the abrupt decadal change component of summer precipitation in East Asia. Science China Earth Sciences 58:404-419

Hoskins BJ, Karoly DJ (1981) The steady linear response of a spherical atmosphere to thermal and orographic forcing. Journal of the Atmospheric Sciences 38:1179-1196

Hsu H, Lin S (2007) Asymmetry of the Tripole Rainfall Pattern during the East Asian Summer. Journal of Climate 20:4443-4458

Huang G (2004) An Index Measuring the Interannual Variation of the East Asian Summer Monsoon-The EAP Index. Adv Atmos Sci 21:41-52

Huang JP, Yi YH, Wang SW, Chou JF (1993) An analogue-dynamical long-range numerical weather prediction system incorporating historical evolution. Quarterly Journal of the Royal Meteorological Society 119:547-565

Huang R, Chen J, Huang G, Zhang Q (2006) The quasi-biennial oscillation of summer monsoon rainfall in China and its cause. CHINESE JOURNAL OF ATMOSPHERIC SCIENCES-CHINESE EDITION- 30:545-556 
Huang R, Zhang Z, Huang G, Ren B (1998) Characteristics of the water vapor transport in East Asian monsoon region and its difference from that in South Asian monsoon region in summer. Chinese $\mathbf{J}$ Atmos Sci 22:469-479

Huang RH Influence of the heat source anomaly over the tropical western Pacific on the subtropical high over East Asia. In. Proc International Conference on the General Circulation of East Asia

Huang RH, Chen JL, Huang G (2007) Characteristics and variations of the East Asian monsoon system and its impacts on climate disasters in China. Advances in Atmospheric Sciences 24:993-1023

Huang RH, Chen JL, Wang L, Lin ZD (2012a) Characteristics, processes, and causes of the spatio-temporal variabilities of the East Asian monsoon system. Advances in Atmospheric Sciences 29:910-942

Huang RH, Liu Y, Feng T (2012b) Interdecadal change of summer precipitation over Eastern China around the late-1990s and associated circulation anomalies, internal dynamical causes. Chinese Science Bulletin 58:1339-1349

Ishii M, Shouji A, Sugimoto S, Matsumoto T (2005) Objective analyses of sea-surface temperature and marine meteorological variables for the 20th century using ICOADS and the Kobe collection. International Journal of Climatology 25:865-879

Kosaka Y, Chowdary JS, Xie S, Min Y, Lee J (2012) Limitations of Seasonal Predictability for Summer Climate over East Asia and the Northwestern Pacific. Journal of Climate 25:7574-7589

Kosaka Y, Nakamura H (2006) Structure and dynamics of the summertime Pacific-Japan teleconnection pattern. Quarterly Journal of the Royal Meteorological Society 132:2009-2030

Kosaka Y, Nakamura H, Watanabe M, Kimoto M (2009) Analysis on the Dynamics of a Wave-like Teleconnection Pattern along the Summertime Asian Jet Based on a Reanalysis Dataset and Climate Model Simulations. Journal of the Meteorological Society of Japan 87:561-580

Kosaka Y, Xie SP, Lau NC, Vecchi GA (2013) Origin of seasonal predictability for summer climate over the Northwestern Pacific. Proceedings of the National Academy of Sciences of the United States of America 110:7574

Lau WKM, Kim K-M (2012) The 2010 Pakistan Flood and Russian Heat Wave: Teleconnection of Hydrometeorological Extremes. Journal of Hydrometeorology 13:392-403

Li H, Dai A, Zhou T, Lu J (2008) Responses of East Asian summer monsoon to historical SST and atmospheric forcing during 1950-2000. Climate Dynamics 34:501-514

Li X, Wen Z, Zhou W, Wang D (2012) Atmospheric Water Vapor Transport Associated with Two Decadal Rainfall Shifts over East China. Journal of the Meteorological Society of Japan Ser II 90:587-602

Lu R, Li Y, Dong B (2006) External and internal summer atmospheric variability in the western North Pacific and East Asia. Journal of the Meteorological Society of Japan 84:447-462

Lu RY (2004) Associations among the components of the East Asian summer monsoon system in the meridional direction. Journal of the Meteorological Society of Japan 82:155 -165

Lu RY, Lin ZD (2009) Role of subtropical precipitation anomalies in maintaining the summertime meridional teleconnection over the western North Pacific and East Asia. Journal of Climate 22:2058-2072

Masao K, Wesley E, Jack W, Shi-Keng Y, J. HJ, M. F, L. PG (2002) Ncep-doe amip-ii reanalysis (r-2). Bulletin of the American Meteorological Society 83:1631-1643

Nitta T (1987) Convective activities in the tropical western Pacific and their impact on the Northern Hemisphere summer circulation. Journal of the Meteorological Society of Japan 65:373-390 
Nitta T, Hu Z (1996) Summer climate variability in China and its association with. J Meteorol Soc Jpn 74:425-445

Qiao S, Gong Z, Feng G, Qian Z (2015) Relationship between cold winters over Northern Asia and the subsequent hot summers over mid-lower reaches of the Yangtze River valley under global warming. Atmospheric Science Letters 16:479-484

Saha S, Moorthi S, Wu X, Wang J, Nadiga S, Tripp P, Behringer D, Hou Y-T, Chuang H-y, Iredell M, Ek M, Meng J, Yang R, Mendez MP, van den Dool H, Zhang Q, Wang W, Chen M, Becker E (2014) The NCEP Climate Forecast System Version 2. Journal of Climate 27:2185-2208

Sato N, Takahashi M (2006) Dynamical processes related to the appearance of quasi-stationary waves on the subtropical jet in the midsummer Northern Hemisphere. Journal of climate 19:1531-1544

Stuecker MF, Jin FF, Timmermann A, McGregor S (2015) Combination Mode Dynamics of the Anomalous Northwest Pacific Anticyclone. Journal of Climate 28:1093-1111

Takaya K, Nakamura H (2001) A Formulation of a Phase-Independent Wave-Activity Flux for Stationary and Migratory Quasigeostrophic Eddies on a Zonally Varying Basic Flow. Journal of the Atmospheric Scienes 58:608-827

Tao S (2006) The Westward,Northward Advance of the Subtropical High over the West Pacific in Summer. Journal of Applied Meteorological Science

Wang B, Fan Z (1994) Choice of South Asian Summer Monsoon Indices. Bulletin of the American Meteorological Society 80:629-638

Wang B, Jian L, Jing Y, Zhou TJ, Wu ZW (2009) Distinct principal modes of early and late summer rainfall anomalies in East Asia. Journal of Climate 22:3864-3875

Wang B, Wu R, Lau KM (2001) Interannual variability of the Asian summer monsoon: contrasts between the Indian and the Western North Pacific-East Asian Monsoons. Journal of climate 14:4073-4090

Wang B, Xiang B, Lee JY (2013) Subtropical high predictability establishes a promising way for monsoon and tropical storm predictions. Proceedings of the National Academy of Sciences 110:2718-2722

Webster PJ, Yang S (1992) Monsoon and ENSO: Selectively interactive systems. Quarterly Journal of the Royal Meteorological Society 118:877-926

Xu Z, Fan K, Wang H (2015) Decadal Variation of Summer Precipitation over China and Associated Atmospheric Circulation after the Late 1990s. Journal of Climate 28:4086-4106

Yang F, Lau KM (2004) Trend and variability of China precipitation in spring and summer: linkage to sea-surface temperatures. International Journal of Climatology 24:1625-1644

Zhou TJ, Wu B, Wang B (2009) How Well Do Atmospheric General Circulation Models Capture the Leading Modes of the Interannual Variability of the Asian-Australian Monsoon? Journal of Climate 22:1159-1173 